NASA Technical Memorandum 105617

AIAA-92-0645

\title{
Comparison of Two-dimensional and Three-dimensional Droplet Trajectory Calculations in the Vicinity of
}

Finite Wings

Stanley R. Mohler, Jr.

Sverdrup Technology, Inc.

Lewis Research Center Group

Brook Park, Ohio

and

Colin S. Bidwell

National Aeronautics and Space Administration

Lewis Research Center

Cleveland, Ohio

Prepared for the

30th Aerospace Sciences Meeting

sponsored by the American Institute of Aeronautics and Astronautics

Reno, Nevada, January 6-9, 1992

\section{N/Sก}





\title{
Comparison of Two-dimensional and Three-dimensional \\ Droplet Trajectory Calculations in the \\ Vicinity of Finite Wings
}

\author{
Stanley R. Mohler, Jr. \\ Sverdrup Technology, Inc. \\ Lewis Research Center Group \\ Brook Park, Ohio 44142
}

\author{
Colin S. Bidwell \\ National Aeronautics and Space Administration \\ Lewis Research Center \\ Cleveland, Ohio 44135
}

\begin{abstract}
$\underline{\text { SUMMARY }}$
Computational predictions of ice accretion on flying aircraft most commonly rely on modeling in two dimensions (2D). These 2D methods treat an aircraft geometry either as wing-like with infinite span, or as an axisymmetric body. Recently, fully threedimensional (3D) methods have been introduced that model an aircraft's true 3D shape. Because 3D methods are more computationally expensive than 2D methods, 2D methods continue to be widely used. However, a 3D method allows us to investigate whether it is valid to continue applying $2 \mathrm{D}$ methods to a finite wing. The extent of disagreement between LEWICE, a 2D method, and LEWICE3D, a 3D method, in calculating Local Collection Efficiencies at the leading edge of finite wings is investigated in this paper.
\end{abstract}

\section{NOMENCLATURE}

b wing span measured directly from tip to tip normal to wing root, $m$

$\mathrm{C}_{\mathrm{D}} \quad$ droplet drag coefficient

c $\quad$ wing chord measured perpendicular to leading edge, $m$

$\mathrm{dA}_{\circ} \quad$ cross-sectional area of 3D droplet flux tube in free stream, $m^{2}$

$\mathrm{dA}_{\mathrm{f}}$ area bounded by intersection of 3D droplet flux tube and surface, $m^{2}$.

dS distance between two intersections of 2D droplet flux tube and airfoil surface, $m$

$\mathrm{dz} \quad$ width of 2D flux tube in the free stream, $m$ 
$\mathrm{K}$ droplet inertia parameter, nondimensionalized by free-stream velocity $\mathrm{U}$, chord $\mathrm{c}$, and air viscosity $\mu$

R droplet Reynolds Number

$\overline{\mathrm{r}} \quad$ droplet position vector, nondimensionalized by chord $\mathrm{c}$

S surface distance between a point on an airfoil and the highlight, $m$

$\overline{\mathrm{u}} \quad$ local flow velocity vector nondimensionalized by free-stream velocity

$\overline{\mathrm{U}} \quad$ free-stream velocity vector, $\mathrm{m} / \mathrm{s}$

y shortest distance between a point on leading edge and the wing root, $m$

$\alpha \quad$ geometric angle of attack, degrees

$\beta \quad$ Local Collection Efficiency

$\beta_{2 \mathrm{D}} \quad$ Local Collection Efficiency computed by 2D method assuming zero wing sweep

$\delta \quad$ droplet diameter, $m$

$\lambda \quad$ wing sweep angle, degrees

$\mu \quad$ air viscosity, $N-s / m^{2}$

p air density, $\mathrm{kg} / \mathrm{m}^{3}$

$\sigma \quad$ mass density of droplet, $\mathrm{kg} / \mathrm{m}^{3}$

$2 \mathrm{y} / \mathrm{b}$ shortest distance between point on the leading edge and the wing root nondimensionalized by wing half-span $b / 2$

(') time derivative of a quantity

\section{Introduction}

Aircraft certified for sustained flight into known icing conditions are equipped with deicing systems to prevent ice from excessively building up on surfaces whose aerodynamic integrity must be maintained for safe flight. Protection of the main wing and horizontal stabilizer is of primary concern. To design deicing systems for wing surfaces, engineers rely on empirical data as well as the computational methods which 
model the physical situation.

A typical computational tool is the NASA LEWICE computer program developed in 1983 by the University of Dayton Research Institute for NASA Lewis, and later modified by Ruff. ${ }^{1}$ To predict the accretion of wing ice, LEWICE and other computational methods follow a 4-step procedure: (1) calculate the flow field about the wing, (2) calculate the trajectories of super-cooled atmospheric droplets and their points of impact on the wing, (3) determine the mass flux of water impinging at surface points, and (4) perform a thermodynamic analysis to determine the amount of ice accretion resulting over a small time increment. This computational procedure can be repeated to build a predicted ice shape. LEWICE has proven quite reliable for predicting experimental rime ice shapes, and somewhat less for glaze shapes. ${ }^{2}$

Until recently, computational methods modeled the icing process in two dimensions. ${ }^{3,4,5,6,7}$ Engineers using a $2 \mathrm{D}$ method analyze a finite wing by selecting chordwise slices of the wing at various locations along the span for individual analysis. The effective angle of attack (or alternatively, the section lift coefficient) for the chosen wing section is input to the $2 \mathrm{D}$ code along with the airfoil coordinates of the selected slice. A unique 2D flow field is calculated for the chosen slice, commonly with a panel method or a finite-difference potential flow solver. Droplet trajectories are calculated in the 2D flow field by numerically integrating Newton's second law of motion for the droplets. As droplets move downstream toward the wing, they are accelerated by air drag caused by their relative "slip velocity," which develops as their paths diverge from the flow streamlines. After trajectories are calculated for a range of upstream starting points, droplet impingement limits are determined at upper and lower chordwise surface locations. Additional trajectories are generated between the tangent trajectories. The distribution of trajectory termination points is used to compute the incident mass flux of water. The mass flux and local flow edge velocities are used in the ice accretion calculation which would follow.

The 2D approach has a number of shortcomings. The approach assumes that geometry variation and flow gradients are negligible in the third dimension (i.e., spanwise). Thus, wings of infinite span (yawed or unyawed) and axisymmetric bodies are perfectly suited for 2D analysis. However, real wings are finite and may be tapered. Real wings also abut fuselages and produce spanwise flow variations unseen by $2 \mathrm{D}$ methods. Finally, the wing tip vortex cannot appear in a 2D model, nor can other effects present near finite wings.

In the quest for greater fidelity, 3D methods ${ }^{8,9,10,11}$ have been introduced recently to address these deficiencies. The 3D methods model all three dimensions of an aircraft structure as well as the engulfing flow field and droplet motion. The Icing and Cryogenic Technology Branch of the NASA Lewis Research Center has developed a three-dimensional droplet impingement and ice accretion code called LEWICE3D ${ }^{12}$. Potapczuk and Bidwell have previously computed ice accretion on a swept MS-317 wing 
using LEWICE3D with satisfactory results.

This paper will describe results of an effort to discover differences in predicted water impingement on finite wings computed with the 2D LEWICE and the LEWICE3D codes. The magnitude of the influence on predicted water impingement of 3D factors such as wing sweep, aspect ratio, taper ratio and proximity of the analyzed section to the wing tip will thereby be revealed.

A baseline case was developed to resemble the wing of a passenger jet in low subsonic flight. The baseline case used a 30 degree swept wing with no fuselage, as shown in Figure 1. The wing of the baseline case had an aspect ratio of 16, where aspect ratio is defined as the total wing area divided by the shortest distance from wing tip to wing tip. The wing has no taper, twist, or dihedral. A NACA 0012 airfoil perpendicular to the leading edge was employed. The free-stream velocity was $134 \mathrm{~m} / \mathrm{s}$ (300 mph). Twenty-micron droplets were impinged at three spanwise sections whose highlights were located at $2 \mathrm{y} / \mathrm{b}=10 \%, 50 \%$, and $90 \%$, where $2 \mathrm{y} / \mathrm{b}=0$ at the wing root and $2 \mathrm{y} / \mathrm{b}=100 \%$ at a tip. The chord measured along the wing root (parallel to the free stream) was four meters. The angle of attack of the wing root was four degrees. Additional cases were run in order to vary wing sweep, aspect ratio, angle of attack, taper ratio, and droplet diameter. In all the cases involving untapered wings, the chord of the wing root was kept at 4 meters. Therefore, the chord as measured perpendicular to the leading edge decreased when wing sweep was introduced. For the tapered case, the root chord was 5.33 meters while the tip chord was 2.67 meters.

\section{Code Description}

The two computer programs introduced in section I. were employed for this study. The LEWICE program performed 2D analyses, and LEWICE3D performed 3D analyses. Since the focus of this study is calculation of water impingement, the thermodynamic and ice accretion routines contained in the codes were not used.

\section{II.A. LEWICE}

LEWICE contains four distinct modules: a flow field solver, a trajectory integration routine, a heat transfer routine, and an ice accretion routine. The present analysis utilized only the flow and trajectory modules.

For solving the flow, LEWICE contains the Hess-Smith panel code to calculate the potential flow about an arbitrary 2D lifting body. Once the panel influence coefficients have been determined, the flow velocity at any point may be determined. Droplet trajectories are calculated from initial points upstream of the body. The droplet equation of motion is a form of Newton's second law where the force on the droplet is 
the aerodynamic drag. LEWICE solves this equation numerically using the predictor-corrector method of Gear. ${ }^{13}$ At each step of the integration, the local flow velocity is calculated by the panel code. The difference between the flow velocity and the droplet's velocity determines the drag on the droplet. The drag force is used by Gear's method to determine an updated position and velocity for the droplet.

As a trajectory develops, the code checks for body impaction. An iterative procedure releases a succession of many trajectories in order to determine two trajectories that graze the upper and lower airfoil surfaces. These "tangent" trajectories terminate at the two surface impingement limits which bound the region containing impinging droplets. Within this region, a series of droplets with evenly spaced initial positions are then released.

The distribution of water impinging over the surface is quantified by the nondimensional mass flux, termed Local Collection Efficiency or beta. Beta is defined as being mathematically equivalent to the infinitesimal cross-sectional area $\mathrm{dA}_{\circ}$ of a mass flux tube in the free stream divided by the surface area $\mathrm{dA}_{\mathrm{f}}$ over which the mass lands (see Figure 2.a.):

$$
\beta=\mathrm{dA}_{\mathrm{o}} / \mathrm{dA}_{\mathrm{f}} .
$$

Computational methods determine approximate values for beta by considering flux tubes of small but finite cross-section. Since a flux tube is bounded by trajectories, computational methods calculate trajectories to determine an approximate value of $\mathrm{dA}_{\mathrm{o}} / \mathrm{dA}_{\mathrm{f}}$. The $2 \mathrm{D}$ methods commonly use a unit distance of depth and compute a $2 \mathrm{D}$ mass flux tube by initiating two trajectories a small distance $\mathrm{dz}$ apart in the free stream (see Figure 1.b.), determining the distance dS between their respective surface impact points, and taking the ratio:

$$
\beta_{2 \mathrm{D}}=\mathrm{dz} / \mathrm{dS} \text {. }
$$

LEWICE determines a value for beta by determining values of $z$ versus $S$, curve fitting the data, and taking the derivative $\mathrm{dz} / \mathrm{dS}$.

The flow field and droplet trajectory calculations are then complete. LEWICE can proceed to use the flow field and beta values along the surface in its ice accretion calculations which are not discussed in this paper. 


\section{II.B. LEWICE3D}

Like LEWICE, the LEWICE3D program constains four disctinct modules. The 3D inviscid flow module in LEWICE3D models a 3D surface by using quadrilateral panels which cover a 3D surface. The flow velocity at any point is calculated by a procedure which sums terms contributed by each panel. Due to the large number of panels, the LEWICE3D panel summation procedure is far more CPU-intensive than the LEWICE procedure. The LEWICE3D summation procedure was vectorized to increase speed for the Lewis Cray XMP computer. The LEWICE3D user inputs the 3D panel model which is read by the 3D first-order Hess-Smith panel code ${ }^{14}$. Each panel possesses uniformly distributed source and dipole strengths. A 3D flow field can be calculated about lifting and non-lifting bodies. Leaking panels can be input to model engine inlets.

The code uses Norment's ${ }^{8}$ droplet trajectory calculation, which employs an Adams-type predictor-corrector method developed by Krogh. ${ }^{15}$ The initial trajectory calculations are part of an iterative search along a line of starting points similar to the LEWICE iteration described in section II.A. in order to determine upper and lower impingement limits.

Subsequent calculations determine beta along the surface. The user may direct LEWICE3D to calculate beta using either a rectangular array of droplet starting points (a 2D array), or a line of starting points (a 1D array). If the user chooses the 1D array option, values of beta are first calculated at the middle of the segments connecting adjacent landing points. Values of beta at additional points are then interpolated from the segment values. If the user chooses the $2 \mathrm{D}$ array option, values of beta are first calculated at the centroids of quadrilaterals whose corners are marked by four adjacent landing points. Values of beta at additional points are then determined by interpolating the centroid betas. These additional points lie either along a surface streamline or along the intersection of a plane and the 3D geometry, as directed by the user.

To reduce compuation time, the $1 \mathrm{D}$ array option was chosen for this study. The The final beta values were chosen to lie along the intersection of the wing and a plane placed normal to the leading edge.

\section{Description of Analysis Methods}

The LEWICE code computes and uses a 2D flow field. The LEWICE user who attempts to predict water impingement on a real aircraft wing assumes that this $2 \mathrm{D}$ flow field will approximate the essential features of the 3D flow field, which the real wing will encounter, to a degree sufficient for LEWICE to produce reasonable water impingement predictions. 
One can immediately question the validity of this assumption. The LEWICE flow field corresponds to the flow in a plane perpendicular to the span of an infinite wing of uniform cross-section. For such a wing, the spanwise flow can be calculated separately, and is simply a constant. However, real wings are finite, may not necessarily possess a uniform cross-section, and features such as taper may significantly affect the flow field.

It would be advantageous to understand whether such features as aspect ratio and taper ratio cause the water impingement on a wing to differ significantly from that predicted by LEWICE. Toward that end, the LEWICE3D icing analysis program was used to predict Local Collection Efficiency on the leading edge of finite wings and the results compared to the predictions of the 2 D LEWICE code.

\section{III.A. Application of 2D Method to Analysis of Finite Wings}

When utilizing a 2D method such as LEWICE to analyze water impingement on a finite wing, proper values of free-stream velocity and section lift coefficient (or alternatively, effective angle of attack) must be input. Determination of the proper values requires the engineer to interpret the meaning of free-stream velocity and pressure coefficient correctly. Similarly, the meaning of the beta output by the code must be interpreted correctly.

As stated above, the flow field of a $2 \mathrm{D}$ method is the flow in a plane perpendicular to the span of an infinitely long wing of uniform cross-section. Therefore, if the wing is yawed by angle $\lambda$, the free-stream velocity of the $2 \mathrm{D}$ flow, which is input to the $2 \mathrm{D}$ code, must be the free-stream velocity component that is perpendicular to the leading edge of the yawed wing: Ucos $\lambda$.

LEWICE computes a 2D flow field to produce the effective angle of attack, or equivalently, the section lift coefficient desired by the user. Note that it is the effective angle of attack, and not the geometric angle of attack, that is desired as input. This becomes apparent when one considers that a finite wing may posses a geometric angle of attack which is constant along the span while the lift, and therefore effective angle of attack, vary along the span. The effective angle of attack may be obtained by a lifting line analysis of the finite wing. Alternatively, the desired section lift coefficient may be obtained by the use of a 3D panel code, as was done for this study.

The section lift coefficient for a wing section defined perpendicular to the leading edge was computed by integrating surface pressures computed by the 3D panel code contained in LEWICE3D. This lift coefficient was input to LEWICE for the 2D analysis. Since the 2D LEWICE flow field is composed of the velocity components lying in a plane perpendicular to the span of an infinite wing, the constant spanwise velocity component is not included in the calculation of pressure and lift coefficients by LEWICE. This constant spanwise component of the free-stream velocity depends solely 
on wing sweep angle. However, the surface pressures computed by the 3D flow code include three velocity components. Therefore, before using the 3D surface pressures to compute a section lift coefficient to input to LEWICE, the 3D surface pressures were adjusted to exclude the influence of the spanwise component of the free stream. The adjustment is achieved by simply dividing the pressure coefficient by the square of the cosine of the wing sweep angle. Kuethe and $\mathrm{Chow}^{16}$ describe this recalculation of pressure coefficient in connection with transonic, yawed wings.

Figure 3 shows the recalculated 3D LEWICE3D surface pressures of a cut made perpendicular to the leading edge of a swept wing. These pressures were integrated to provide the section lift coefficient input to LEWICE. The surface pressures subsequently output by LEWICE appear in the same plot. Note that the two pressure distributions appear only slightly different from each other.

Once LEWICE has computed the flow field, droplet trajectories are calculated. Dorsch and Brun ${ }^{17}$ described how to calculate 2D droplet trajectories incident on an infinite yawed wing. In 3D, the non-dimensional droplet trajectory equation of motion, ignoring gravity, is written as:

$$
K \ddot{\bar{r}}=\left(C_{D} R / 24\right)(\overline{\mathrm{u}}-\dot{\overline{\mathrm{r}}})
$$

where

$$
K=\sigma \delta^{2} U / 18 c \mu
$$

and

$$
R=\rho \delta U|| \overline{\mathrm{u}}-\dot{\bar{r}}|| / \mu .
$$

The free-stream velocity $\bar{U}$ is not aligned perpendicular to the leading edge if the wing is yawed. Dorsch and Brun show that for a wing of infinite span yawed by an angle $\lambda$, the above equations can be solved in two dimensions if the component of the free stream perpendicular to the leading edge, $U \cos \lambda$, replaces $U$ in the equations above to calculate the two droplet parameters $\mathbf{K}$ and $\mathbf{R}$. Accordingly, for the baseline case, the free-stream velocity of $134 \mathrm{~m} / \mathrm{s}$ was multiplied by the cosine of the sweep angle of 30 degrees to produce the value for free-stream velocity input to LEWICE. The chord was measured perpendicular to the leading edge. The input airfoil coordinates defined the intersection of the wing with a plane cutting normal to the leading edge. This airfoil was NACA 0012 .

LEWICE outputs values of beta defined by equation (1b). As stated previously, this equation is equivalent to equation (1a) for a wing of infinite span and no yaw. 
However, if the user is modeling a yawed wing, equation (1b) is modified. With yaw, the beta will be less than that computed by equation (1b). This becomes apparent when one realizes that the intersection of a flux tube of infinitely massive particles with an infinite wing bounds a larger area of the surface when wing yaw is increased. Since this increased surface area represents a wider distribution of a fixed amount of water per unit time, the amount of water landing on a unit area decreases with wing sweep. The equation to be used with equation (1b) states:

$$
\beta=\beta_{2 \mathrm{D}} \cos \lambda .
$$

Local Collection Efficiencies were output by LEWICE and corrected for wing sweep using equation (3).

\section{III.B. Application of 3D Method to Analysis of Finite Wings}

The baseline panel model consisted of approximately 2000 panels per half-body. Each trajectory required on the order of $200 \mathrm{CPU}$-seconds to compute on the Lewis Cray XMP computer. The three beta curves of the baseline case, shown in Figure 4.a., were calculated at cuts which sliced perpendicular to the leading edge at $10 \%, 50 \%$, and $90 \%$ of the distance from the wing root to the wing tip, respectively. The three curves appeared virtually identical. The option for a $1 \mathrm{D}$ array of starting points, described in section II.B., was used in this report in order to decrease computational workload.

The starting points of tangent trajectories are found to within a tolerance specified by the user. The 1D array of starting points was placed between these points. LEWICE3D searches for these impingement limits using a simple back-and-forth search. However, the iteration was not very efficient at the time of this study. Fairly loose tolerances were specified in order to minimize computation time and user supervision of the process. As a result, the impingement limits produced by LEWICE3D in this paper are less precise than those of LEWICE due to LEWICE3D imprecisely identifying tangent trajectories.

The LEWICE3D code presently includes a "DSHIFT" feature generally similar to the one built into the production LEWICE code. This feature generates a pseudo surface which lies slightly off the body by a user-controlled distance DSHIFT in the vicinity of the leading edge. Trajectories are assumed to land on this surface and are terminated upon impact with it. The purpose is to eliminate the need to calculate flow velocities so close to panel surfaces that the singularities there generate unreasonably high values. The pseudo surface generated by the production version of LEWICE is slightly different from that currently encoded into LEWICE3D. The pseudo surface of LEWICE3D is created by translating panel corner points a distance DSHIFT in the free- 
stream direction (upstream). For the calculations in this paper, LEWICE was modified to create its pseudo surface in the same manner as LEWICE3D. Values of DSHIFT were chosen so that the pseudo surface would lie a distance of 0.002 of the root chord from the leading edge, where the chord and the distance are measured in the free-stream direction.

\section{Results and Discussion}

\section{IV.A. Three-dimensional Analysis}

Several parameters were explored in the 3D trajectory analysis of the finite NACA 0012 airfoil. These parameters included: spanwise location, aspect ratio, angle of attack, sweep angle, taper ratio and droplet size. In the following section, the effect of these variables upon the collection efficiency and pressure coefficient will be discussed.

Note that in all Local Collection Efficiency plots in this paper, surface distances are zero at the highlight and are positive over the lower surface. The Local Collection Efficiency curves produced by LEWICE3D drop to zero at impingement limits which were determined imprecisely, due to reasons described in section III.B. However, the plots were computed accurately wherever values are nonzero. Also note that the pressure coefficients in all plots have been calculated based on the component of the free stream normal to the leading edge, as explained in section III.A.

\section{IV.A.1. Results of Varying Spanwise Location}

Figures 4 and 5 show the spanwise variation of Local Collection Efficiency for all the cases, and pressure coefficient for some selected cases. In general the spanwise variation of Local Collection Efficiency and pressure coefficient was small for all of the cases except the taper ratio case. For the taper ratio case the spanwise variation of Local Collection Efficiency was expected because of the spanwise variation in chord of the geometry. It was also expected that for cases with small spanwise variation in pressure coefficient, there would be little variation in Local Collection Efficiency and this was brought out in the result. The one surprising result was that for the aspect ratio 2 case (Fig 4c), where the greatest variation of the shape of the pressure distribution was noted, there was no significant variation in Local Collection Efficiency. After further consideration the result may be reasonable if the small spanwise variation in lift, which varies as the area enclosed by the upper and lower surface curves, can be thought of as a spanwise variation in effective angle of attack. This spanwise variation in effective angle of attack would be relatively small compared to the higher aspect ratio cases. 


\section{IV.A.2. Results of Varying Aspect Ratio}

Figures 6 and 7 show the variation of Local Collection Efficiency and pressure distribution as a function of aspect ratio at the $2 \mathrm{y} / \mathrm{b}=50 \%$ location. The Local Collection Efficiency for all of these cases agree well with the aspect ratio 2 case showing the most difference. The pressure distribution for the cases also agree well except for the aspect ratio 2 case. The difference between the upper and lower pressures is noticeably smaller for this case. This observation is consistent with the fact that section lift coefficient decreases with aspect ratio for a finite wing. This falling off of the lift coefficient can again be thought of as a reduction in effective angle of attack and be used to explain the difference in the Local Collection Efficiency plots. A reduction in angle of attack causes the maximum Local Collection Efficiency to increase and the Local Collection Efficiency peak to shift more towards the highlight.

\section{IV.A.3. Results of Varying Angle of Attack}

The variation of Local Collection Efficiency and pressure distribution with angle of attack is shown in Figures 8 and 9. The trends observed here are consistent with 2D results. The maximum Local Collection Efficiency decreases with angle of attack and the point where it occurs moves more towards the underside of the airfoil. Also consistent is the migration of the entire impact region to the underside of the airfoil. This migration of the impact region is in response to the migration of the stagnation zone with angle of attack.

\section{IV.A.4. Results of Varying Sweep Angle}

The effect of sweep angle on Local Collection Efficiency and pressure distribution is shown in Figures 10 and 11. From these figures we see that as we increase sweep angle the maximum Local Collection Efficiency decreases. Several factors contribute to this decrease. From one perspective, the free-stream velocity component normal to the leading edge decreases with sweep, leading to a decrease in the inertia parameter of the particles as described by Dorsch and Brun ${ }^{17}$. A lower inertia parameter allows the flow to deflect droplets around the wing more easily. From another perspective, consider a particle with infinite inertia. The particle paths which intersect the body will be straight lines. If we consider four impacting trajectories along a square flux tube we can calculate the Local Collection Efficiency as the ratio of the cross-sectional area of the tube to the area outlined by the four impacting trajectories at the surface. As we increase the sweep angle of the surface the only effect is to increase the impacting surface area spanwise by the inverse of the cosine of the sweep angle. Hence the effect of is to decrease the Local Collection Efficiency by the cosine of the sweep angle (see equation 3 ). 


\section{IV.A.5. Results of Varying Taper Ratio}

Figures 12 and 13 show the affect of taper ratio on Local Collection Efficiency and pressure distribution. The analyzed spanwise location was at $2 \mathrm{y} / \mathrm{b}=50 \%$ for both the untapered and tapered cases. The chord measured perpendicular to the leading edge at the $2 \mathrm{y} / \mathrm{b}=50 \%$ location was also the same for both cases. Thus taper was achieved by increasing the root chord of the panel model beyond 4 meters to 5.33 meters while reducing the wing tip chord to 2.67 meters. Figure 12 shows that the affect of introducing taper is to reduce the Local Collection Efficiency by about $10 \%$ over most of the impinged surface distance, which is mostly on the lower surface. The pressure plot in Figure 13 does not offer an obvious explanation for this.

\section{IV.A.6. Results of Varying Droplet Size}

The effect of droplet size or inertia parameter on Local Collection Efficiency can be seen in Figure 14. The droplet sizes ranged from 15 microns to 100 microns. Under the conditions used, this corresponds to a range of modified inertia parameters from 0.0086 to 0.159 . From the figures we see that as we increase droplet size the Local Collection Efficiency and the extent of impingement increases. This trend is also consistent with 2D results. As the drop size or inertia of the drop increases its path is less likely to be affected by the airfoil flow-field disturbance and hence it will impact farther back on the airfoil and cause larger Local Collection Efficiencies.

\section{IV.B. Comparison of Three-dimensional Analysis with Two-dimensional Analysis}

A selection of 3D results was chosen for comparison with the results of 2D analysis. Since little spanwise variation in Local Collection Efficiency was seen in the 3D analysis, the selection was chosen to consist of all 3D calculations performed at the $2 \mathrm{y} / \mathrm{b}=50 \%$ location. The 2D analysis will be described in five parts. Each part includes the baseline case and one or two other cases for which a chosen input parameter was allowed to vary from the baseline. These parameters were sweep angle, aspect ratio, angle of attack, taper ratio, and droplet size.

\section{IV.B.1. Results of Varying Sweep Angle}

Figure 15a shows a comparison of the beta curves produced by LEWICE3D and LEWICE for the baseline case for which wing sweep angle was 30 degrees. The peak betas agree very well. The 2D method predicts a slightly higher Local Collection Efficiency along the lower surface. 
Figure $15 \mathrm{~b}$ shows the surface pressures predicted by the $3 \mathrm{D}$ code and the $2 \mathrm{D}$ code. As with all the pressure plots in this paper, the pressure coefficients have been calculated as by Kuethe and Chow, described in section III.A. of this paper. Though the 2D pressure distribution in the figure yields the same section lift coefficient as the 3D distribution, it can be seen that the resulting $2 \mathrm{D}$ surface pressures reach a slightly more negative peak. This becomes more clear in Figure $15 \mathrm{c}$ which shows a closeup of the pressures at the leading edge.

Figure 16a shows the Local Collection Efficiency comparison when the wing is unswept. This particular case was situated at $2 \mathrm{y} / \mathrm{b}=10 \%$ rather than $50 \%$. The $10 \%$ location was chosen so that the 3D flow field would most closely resemble a $2 \mathrm{D}$ flow field for this case than for any of the 3D cases appearing in this paper. This resemblance was expected because the 3D flow field in a plane normal to the leading edge approaches a 2D flow field when the plane is situated at $2 \mathrm{y} / \mathrm{b}=0$ and the aspect ratio becomes very large. Furthermore, the lack of wing sweep in this case eliminates the 3D affect of the airflow's need to negotiate a bend in the wing planform. Since the present wing's aspect ratio was fairly high and the spanwise location was very close to $2 \mathrm{y} / \mathrm{b}=0$, it follows that the calculation depicted in the figure employed a highly twodimensional flow field. Inclusion of this case allows one to see how closely the 2D and $3 \mathrm{D}$ results agree when the $3 \mathrm{D}$ flow field is as similar to the $2 \mathrm{D}$ flow field as possible. The figure shows that the 2D and 3D methods agreed extremely well on the peak value while the 2D method appeared to predict a slightly higher beta along the lower surface. The 2D and 3D curves for this case appear to compare to each other as in the baseline case. Therefore, it would appear that the presence of wing sweep in the baseline case (see Figure 15) did not contribute any significant 3D influence on Local Collection Efficiency after all.

Figures $16 \mathrm{~b}$ and $16 \mathrm{c}$ show the surface pressures for the unswept case. The $2 \mathrm{D}$ and 3D surface pressures compare to each other as they did for the baseline case (see Figure 15b).

\section{IV.B.2. Results of Varying Aspect Ratio}

The baseline case used an aspect ratio of 16 . Figures $17 \mathrm{a}$ and $\mathrm{b}$ show the beta curves for aspect ratio 8 and 2 respectively. For aspect ratio 8 , the $2 \mathrm{D}$ and $3 \mathrm{D}$ peak betas agree very closely. The 2D method predicts slightly higher betas over the lower surface, though not by as much as in the baseline case. When the aspect ratio is reduced down to 2, the two curves agree extremely well over the entire impinged surface, except near the impingement limits due to reasons described in section III.B.

Figure 18 shows the surface pressures calculated by the $2 \mathrm{D}$ and $3 \mathrm{D}$ methods. The 2D and 3D peak values on the upper surface are noticeably different. However, this does not appear to have induced the 2D and 3D beta curves to disagree appreciably. 


\section{IV.B.3. Results of Varying Angle of Attack}

The root section of the baseline case was set to four degrees angle of attack. The angle of attack was reset to 0 and 8 degrees to produce the $3 \mathrm{D}$ calculations depicted in Figures $19 \mathrm{a}$ and $19 \mathrm{~b}$ respectively. The 0 degree case shows that the $2 \mathrm{D}$ method again predicted the same peak value of beta as the $3 \mathrm{D}$ method while predicting slightly higher values away from the peak. When the angle of attack is increased to 8 degrees, we see that the 2D method is still predicting the same peak value while slightly mismatching elsewhere. Figure 19b shows that the $2 \mathrm{D}$ method predicted slightly higher values over part of the lower surface while predicting slightly lower values elsewhere. Figure 20 shows the pressures distributions for the two cases.

\section{IV.B.4. Results of Varying Taper Ratio}

The baseline case had a wing taper ratio of 1 . Thus the tip chord was equal to the root chord. A case was run for which the taper ratio was set to 0.5 , i.e., the tip chord was half that of the root chord with a linear variation along the span. For both cases, the chord at the $2 \mathrm{y} / \mathrm{b}=50 \%$ location were the same. Thus, for the tapered wing, the root chord was set to 5.33 meters while the tip chord was one-half of that. Figure 21a shows the beta curves that resulted for this case. The 2D method predicts a slightly higher peak value while predicting a substantially higher beta over the lower surface. It was noticed that for flow in the plane perpendicular to the leading edge, the $2 \mathrm{D}$ stagnation point was situated further along the lower surface from the highlight than was the $3 \mathrm{D}$ stagnation point by about 0.006 nondimensional units. This may explain why much of the $2 \mathrm{D}$ beta curve appears to be displaced to the right of the $3 \mathrm{D}$ curve in the figure by about that distance.

The 2D surface pressure was more negative than the 3D pressure near the leading edge, as evident in Figure 21b. It is not immediately apparent that any conclusions can be drawn from the pressure plot.

\section{IV.B.5. Results of Varying Droplet Size}

Cases were run for a range of droplet sizes. Figure 22 shows the $2 \mathrm{D}$ and $3 \mathrm{D}$ beta predictions for droplets of 15,30 , and 100 microns. It is evident that for this wide range of droplet sizes, the 2D and 3D peak beta values tend to agree while the 2D method tends to predict a slightly higher Local Collection Efficiency over most of the surface. 


\section{Conclusion}

The LEWICE3D and 2D LEWICE droplet trajectory and icing analysis codes were used to predict Local Collection Efficiencies for finite NACA 0012 wings. As aspect ratio, wing sweep, angle of attack, taper ratio, and droplet size were varied, a series of trends were produced by LEWICE3D. Comparisons were made with the predictions of the 2D LEWICE code.

LEWICE3D predicted how Local Collection Efficiency varied along the span of finite wings of various shapes under a variety of conditions. It was found that in each case, the Local Collection Efficiency tended to vary little over $90 \%$ of the span unless taper was introduced to the wing. Increasing the sweep angle of a wing reduced the Local Collection Efficiency. Increasing the angle of attack reduced the peak value while shifting and stretching the region of impingement. Increasing droplet size tended to increase the extent of surface impinged as well as the magnitude of impingement. The peak Local Collection Efficiency varied along the span of a tapered wing, increasing as the wing tips were approached.

After analyzing finite NACA 0012 wings with the 2D LEWICE code, it was seen that the predictions agreed closely with LEWICE3D for a range of aspect ratios, wing sweep angles, angles of attack, and droplet sizes. Some disagreement between results may have been caused by the fact that under similar circumstances, the effective angle of attack computed by a 2D method is not always equal to the 3D angle. The stagnation points computed by the two methods may similarly disagree. Perhaps the most important result concerned wing taper. For a tapered wing the predicted Local Collection Efficiencies calculated by LEWICE3D and LEWICE disagreed noticeably. The result seemed to correspond to a disagreement in the location of the stagnation point predicted by each method. It would appear that the inability of LEWICE to calculate the true 3D flow field for a finite wing caused the disagreement in results for a tapered wing.

Since aircraft commonly have tapered wings, further investigations should be made into the effect of taper on Local Collection Efficiency. Airfoils other than a NACA 0012 have yet to be investigated. The applicability and limitations of the 2D droplet trajectory methods might thereby become clear. 


\section{REFERENCES}

1. Ruff, G.A. and Berkowitz, B.M., "User's Manual for the NASA Lewis Ice Accretion Prediction Code (LEWICE)," NASA CR 185129, May, 1990.

2. Berkowitz, B.M. and Riley, J.T., "Analytical Ice Shape Predictions for Flight in Natural Icing Conditions," NASA CR 182234, 1989.

3. McComber, P. and Touzot, G., "Calculation of the Impingement of Cloud Droplets on a Cylinder by the Finite-element Method," Journal of Atmospheric Sciences, vol. 38, 1981.

4. Bragg, B.B., "Rime Ice Accretion and Its Effect on Airfoil Performance," NASA CR 165599, Mar. 1982.

5. Lozowski, E.P., and Oleskiw, M.M., "Computer Modeling of Time-dependent Rime Icing in the Atmosphere," CRREL 83-2, Jan. 1983.

6. Gent, R.W., "Calculation of Water Droplet Trajectories About an Aerofoil in Steady Two-Dimensional, Compressible Flow," RAE TR 84060, Jun. 1984.

7. Stock, H.W., "Water Droplet Trajectory Computation about an Air Intake," Zeitschriftfur Flugwissenschaften und Weltraumforschung, Band 8, 1984.

8. Norment, H.G., "Calculation of Water Drop Trajectories to and About Arbitrary Three-Dimensional Bodies in Potential Airflow," NASA CR 3291, Aug. 1980

9. Kim, J.J., "Particle Trajectory Computation on a 3-D Engine Inlet," NASA CR175023, DOT-FAA-CT-86-1, Jan. 1986.

10. Craig, N., Vu, S., Breer, M., "3-D Particle Trajectory Analysis (PTA) Code User's Manual," Boeing Doc. No. D500-12189-1, Feb. 1990.

11. Mohler, S.R., "A Three-dimensional Droplet Trajectory Program for Aircraft Icing Analysis," M.S. Thesis, The Ohio State University, 1990.

12. Potapczuk, M.G. and Bidwell, C.S., "Numerical Simulation of Ice Growth on a MS-317 Swept Wing Geometry," AIAA Paper 91-0447, Jan. 1991.

13. Gear, C.W., "DIFSUB for Solution of Ordinary Differential Equations," Comm. $A C M$, Mar. 1971. 
14. Hess, J.L. and Smith, A.N.O., "Calculation of Potential Flow About Arbitrary Bodies," Progress in Aeronautical Sciences, Vol. 8, edited by D. Kuchemann, Pergammon Press, New York, 1967.

15. Krogh, F.T., "Variable Order Integrators for Numerical Solutions of Ordinary Differential Equations," Jet Propulsion Lab Technology Utilization Document No. CP-2308, Nov. 1970.

16. Kuethe, A.M. and Chow, C.-Y., Foundations of Aerodynamics, Wiley, New York, 1986.

17. Dorsch, R.G. and Brun, R.J., "A Method for Determining Cloud Droplet Impingement on Swept Wings," NACA TN 2931, Apr. 1953. 


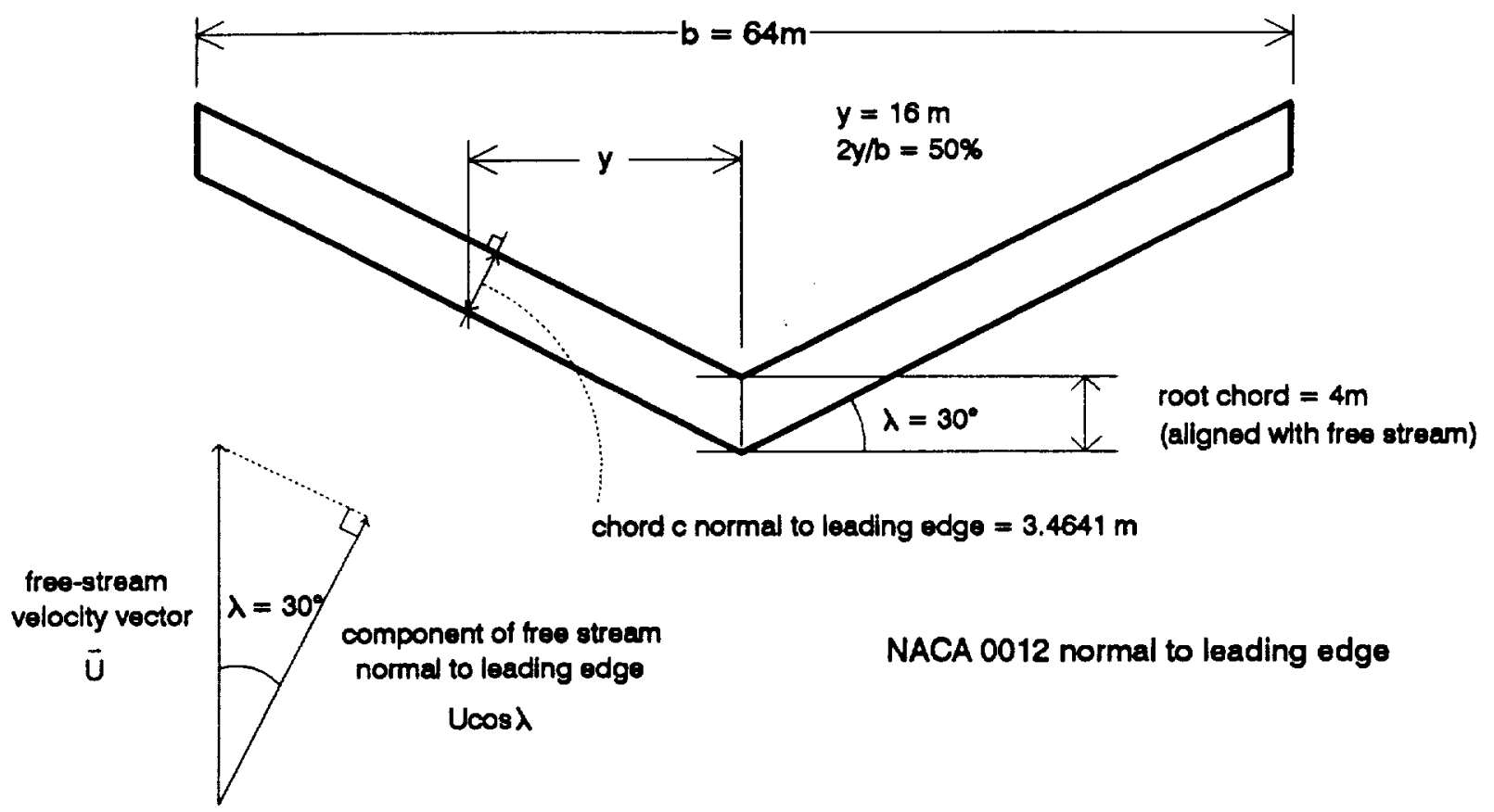

(a) Planform view.
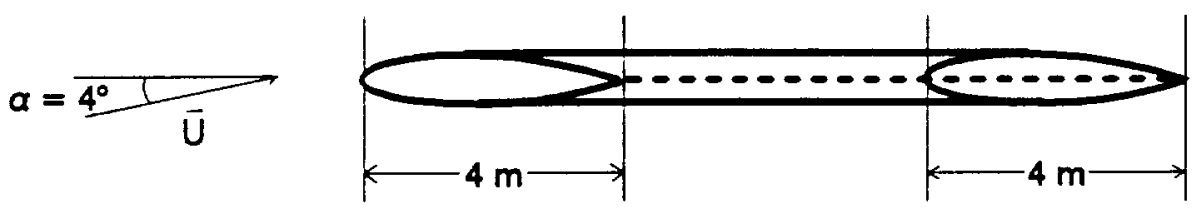

(b) Side view.

Figure 1. - Description of baseline geometry. 


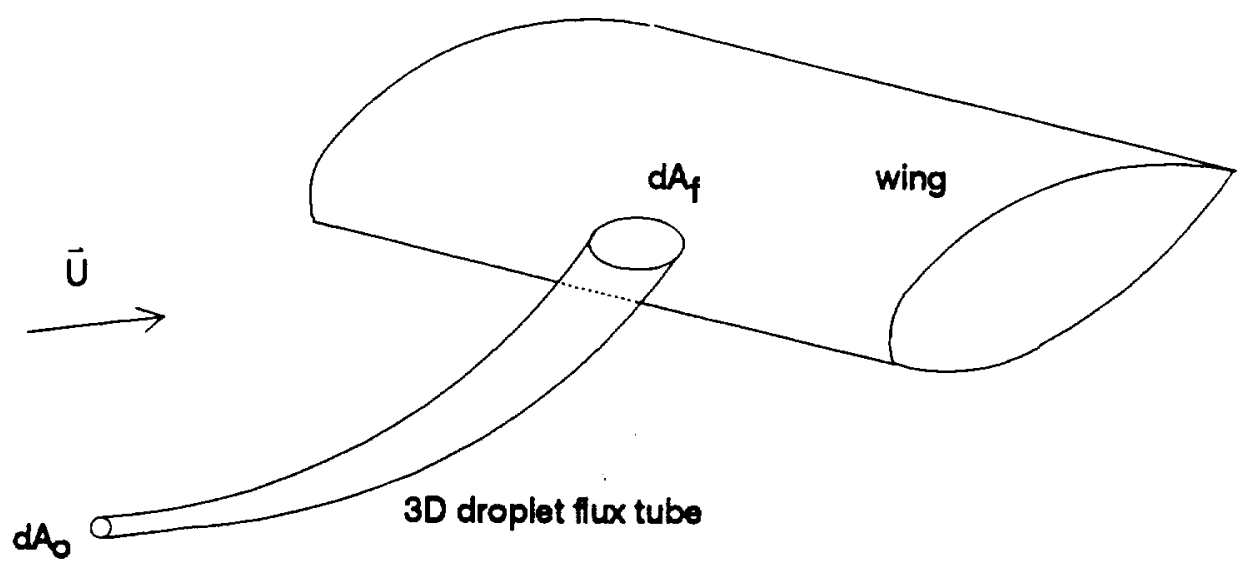

(a) Terms used in 3D definition.

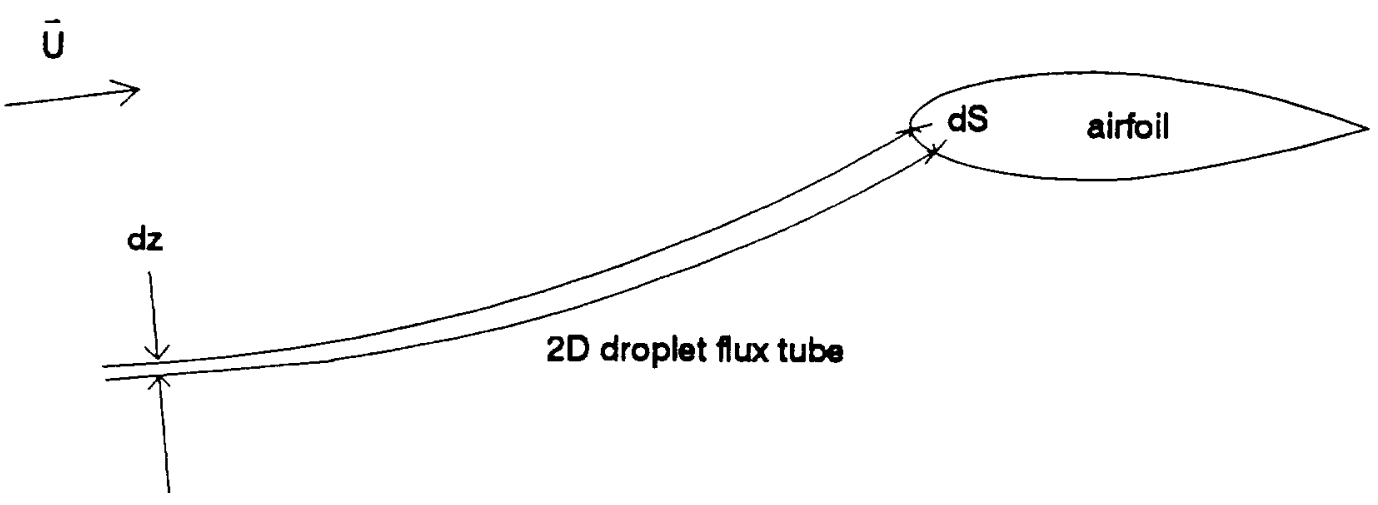

(b) Terms used in 2D definition.

Figure 2. - Definition of terms used to define Local Collection Efficiency. 


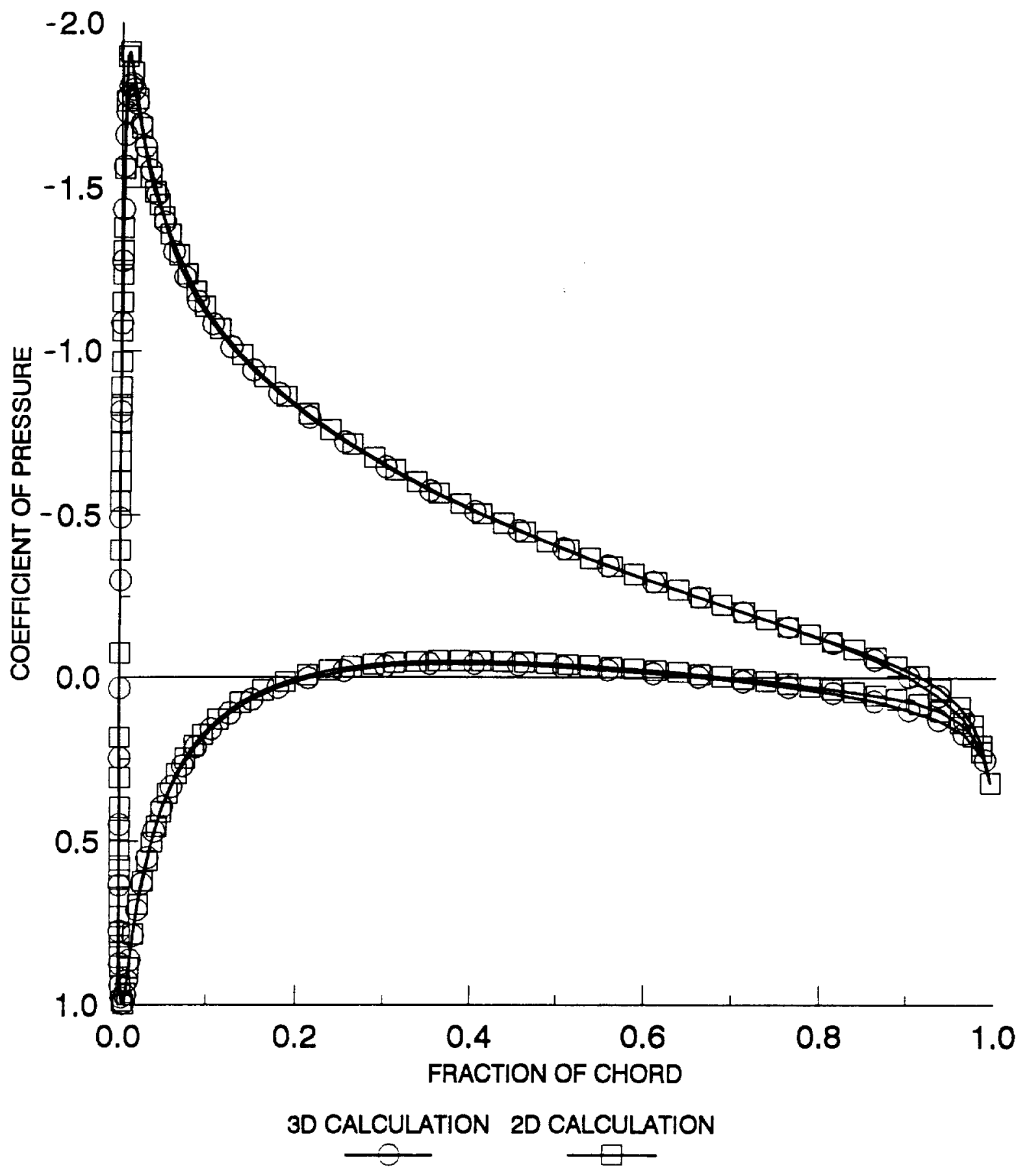

Figure 3. - Comparison of surface pressures predicted by LEWICE and LEWICE3D for NACA 0012 swept $30^{\circ}$; taper ratio $=1$; angle of attack of root chord $=4^{\circ}$.

Calculations were based on component of free stream normal to leading edge. 


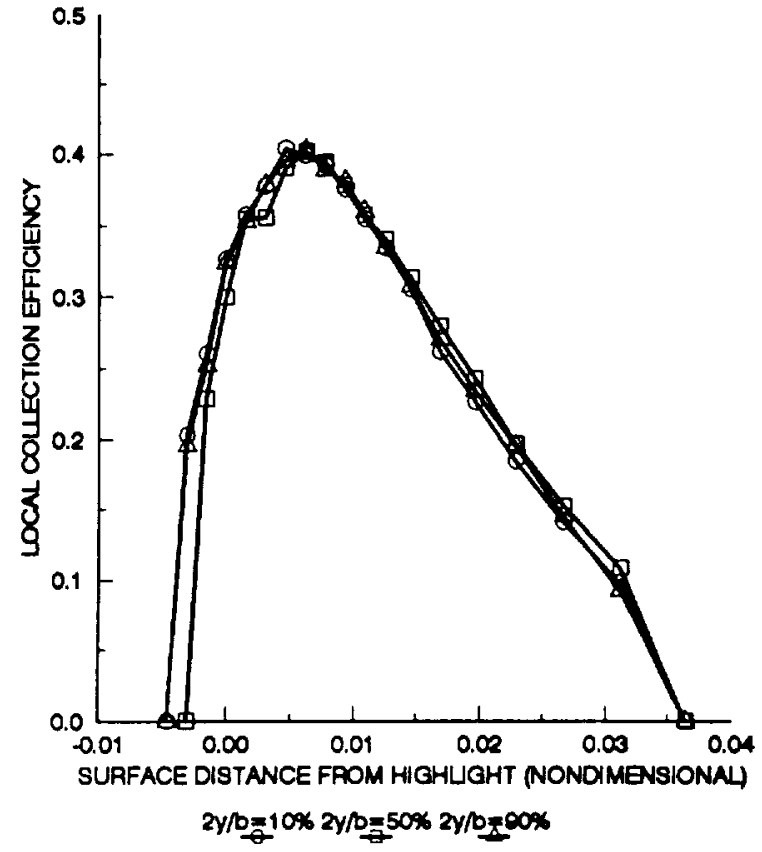

(a) Baseline case; root chord angle of attack $=4^{\circ}$, sweep angle $=30^{\circ}$, aspect ratio $=16$, taper ratio $\stackrel{1}{=} 1$.

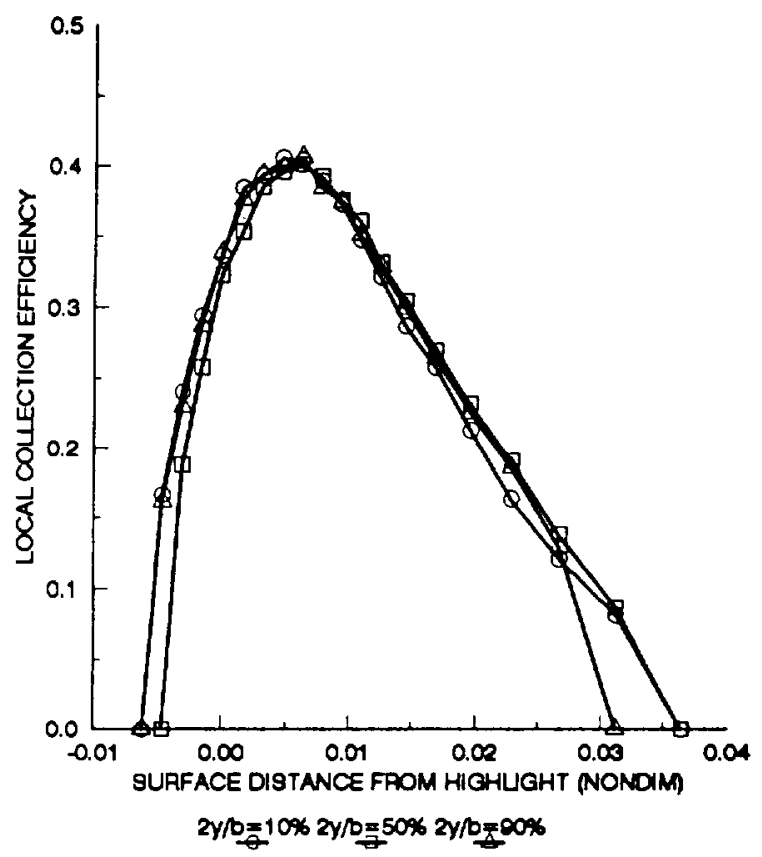

(b) Case for which aspect ratio $=8$.

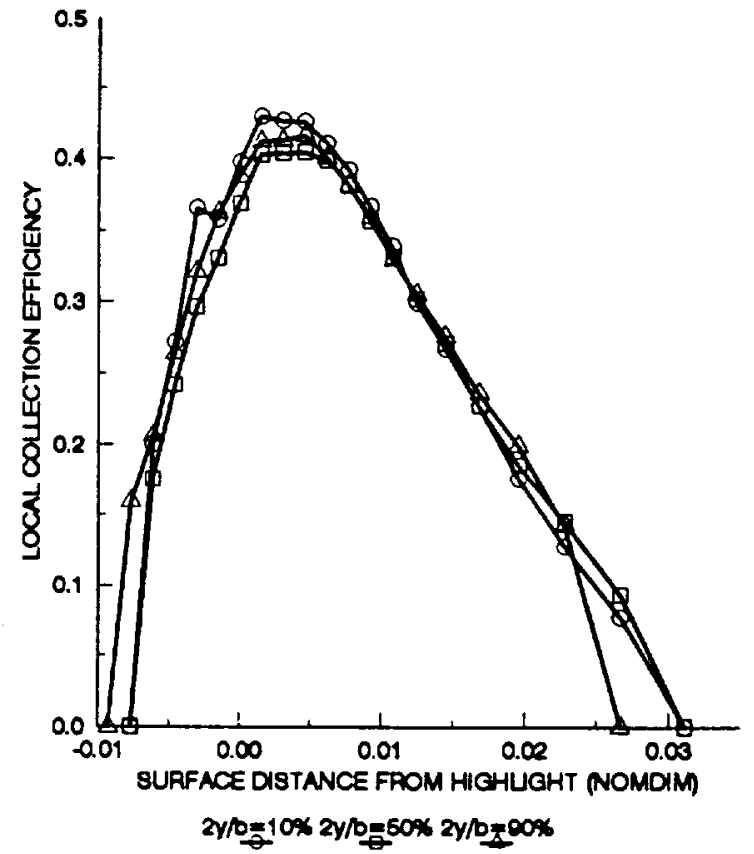

(c) Case for which aspect ratio $=2$.

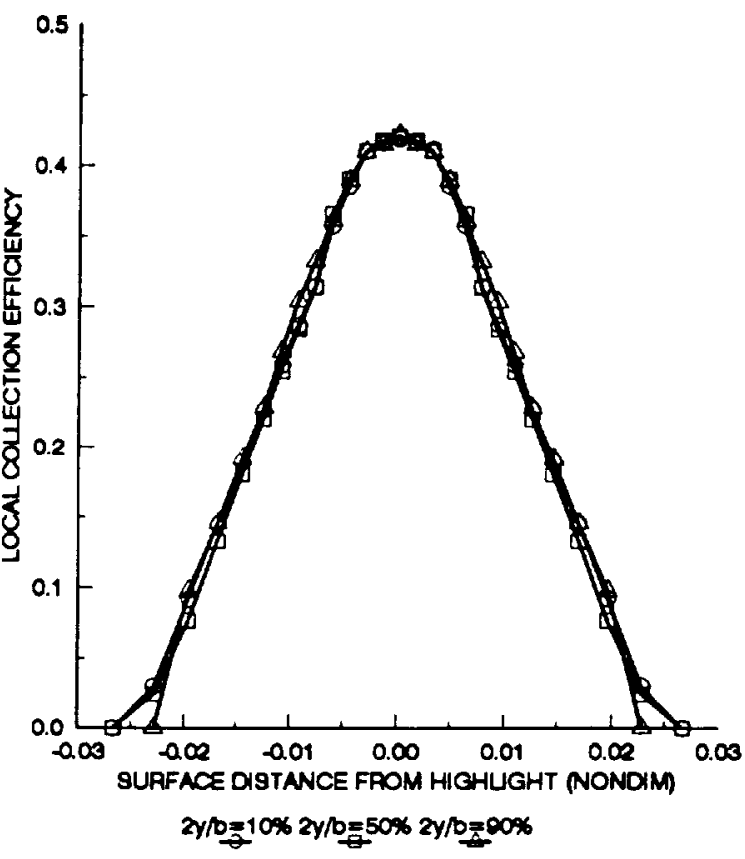

(d) Case for which angle of attack $=0$.

Figure 4. - Predicted spanwise variation of Local Collection Efficiency for NACA 0012 (LEWICE3D). Airspeed $=134 \mathrm{~m} / \mathrm{s}$ (300 mph), droplet size $=20$ microns. Surface distance is positive over lower surface. 


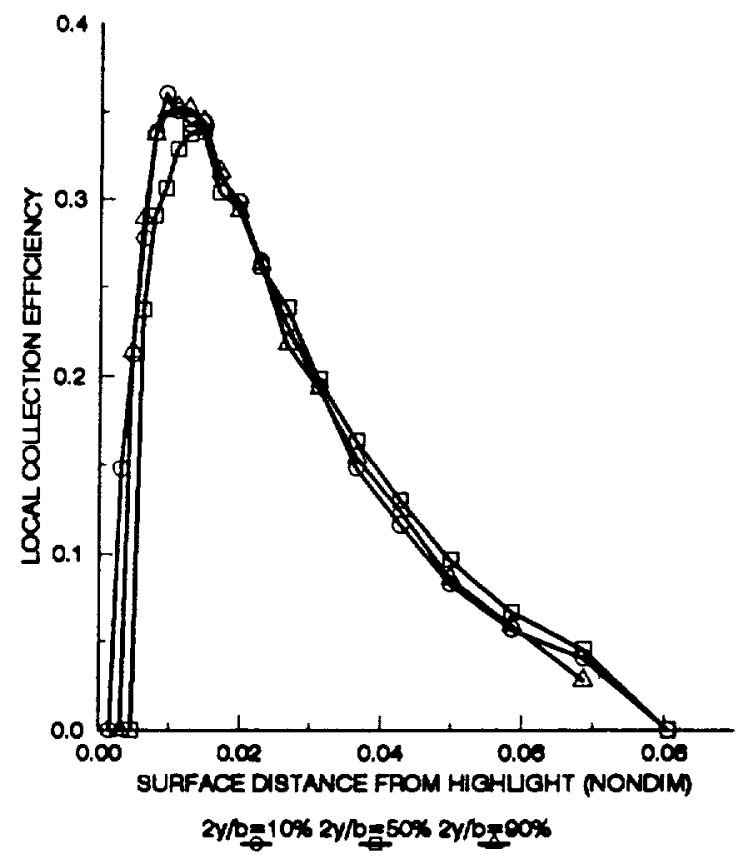

(e) Case for which angle of attack $=8^{\circ}$.

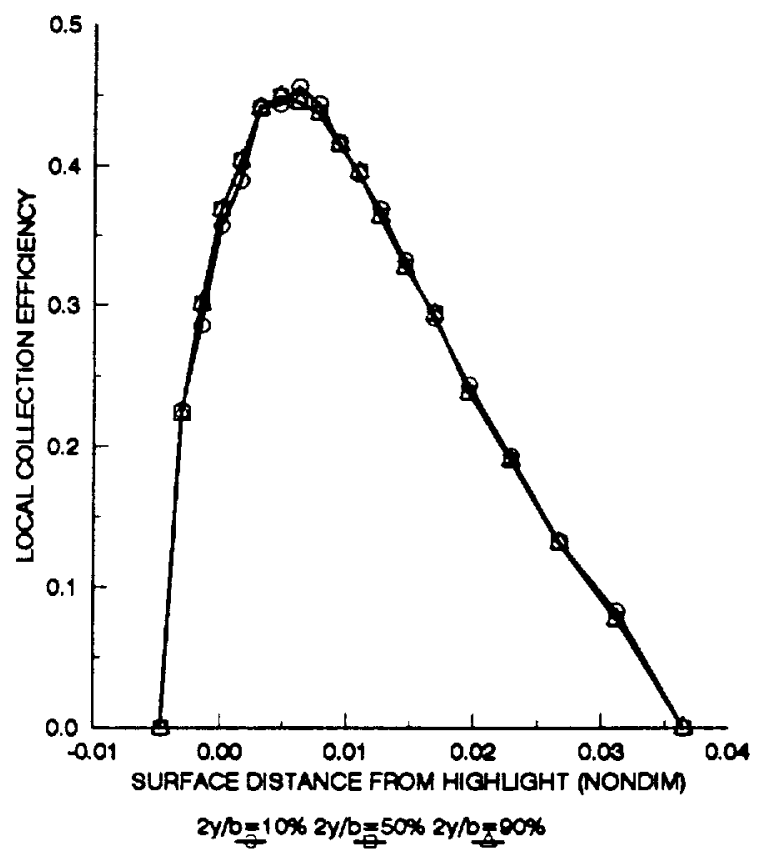

(f) Case for which wing sweep $=0^{\circ}$.

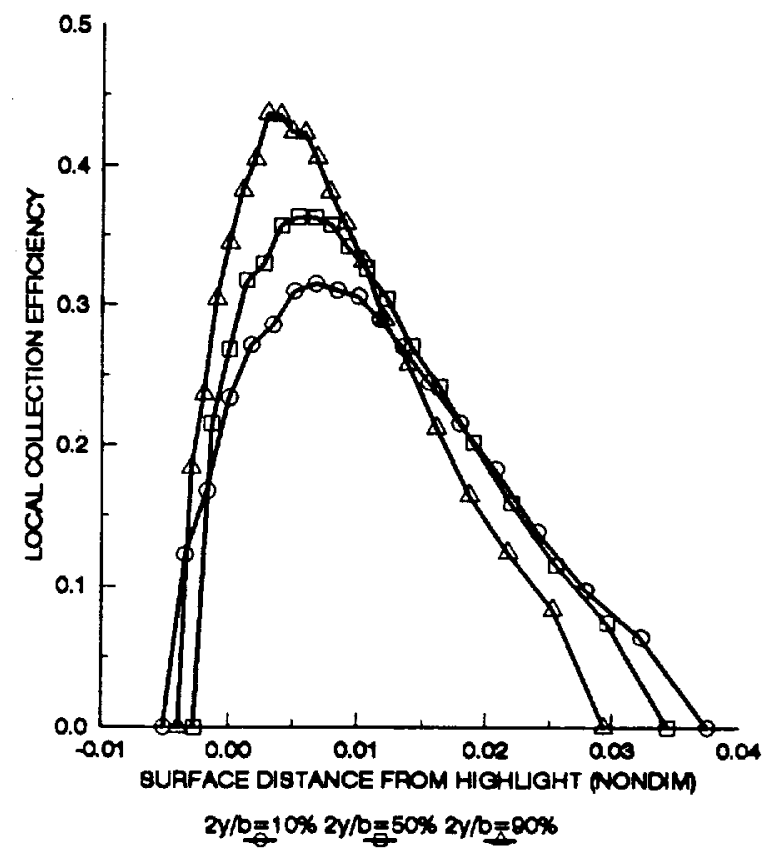

(g) Case for which taper ratio $=0.5$. 


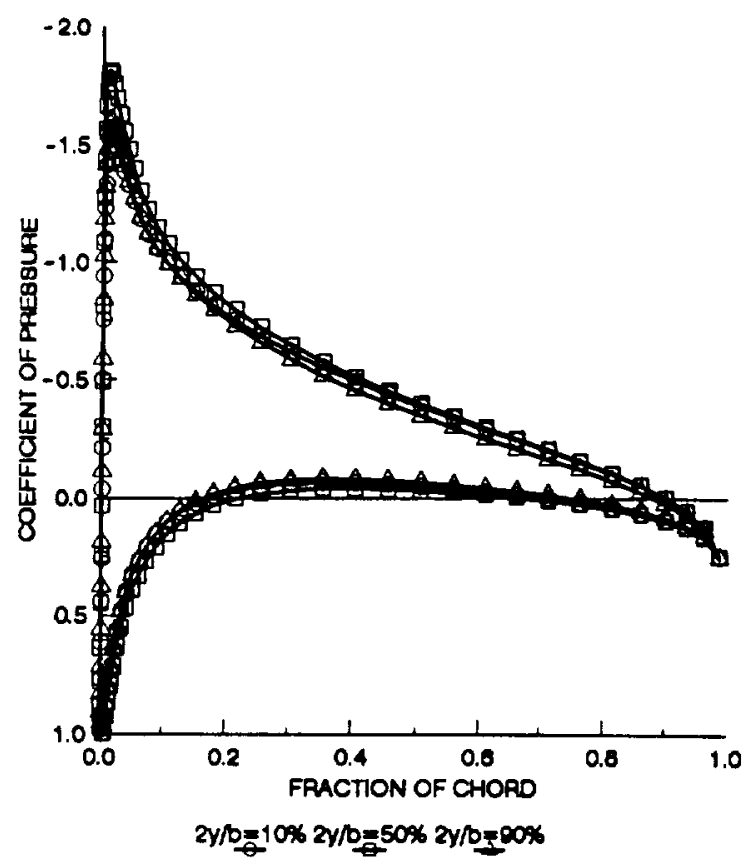

(a) Baseline case; aspect ratio $=16$; taper ratio $=1 ;$ wing sweep angle $=30^{\circ}$.

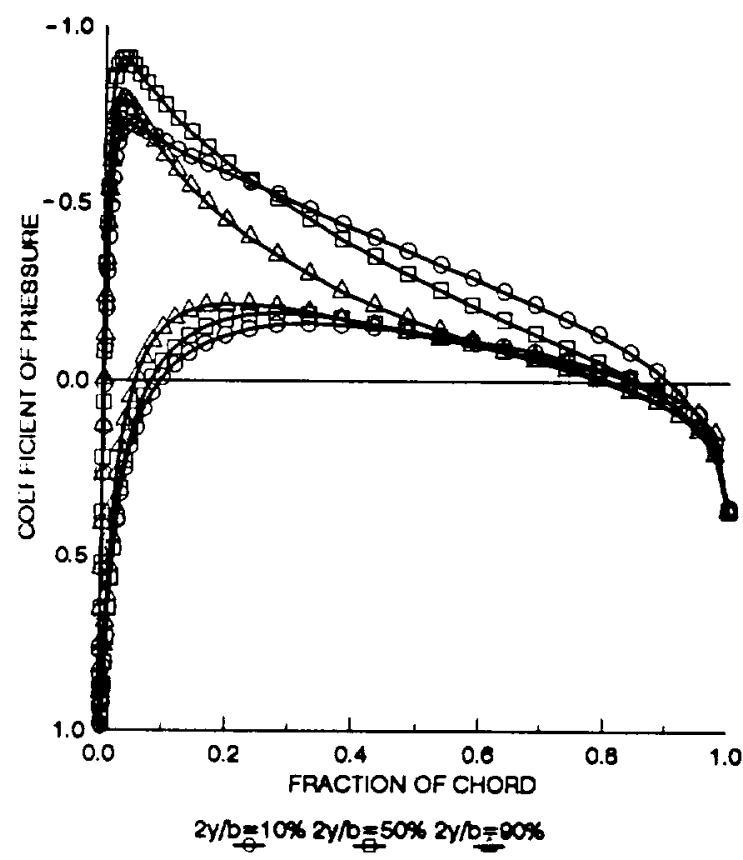

(b) Aspect ratio $=2$; taper ratio $=1$; wing sweep angle $=30^{\circ}$.

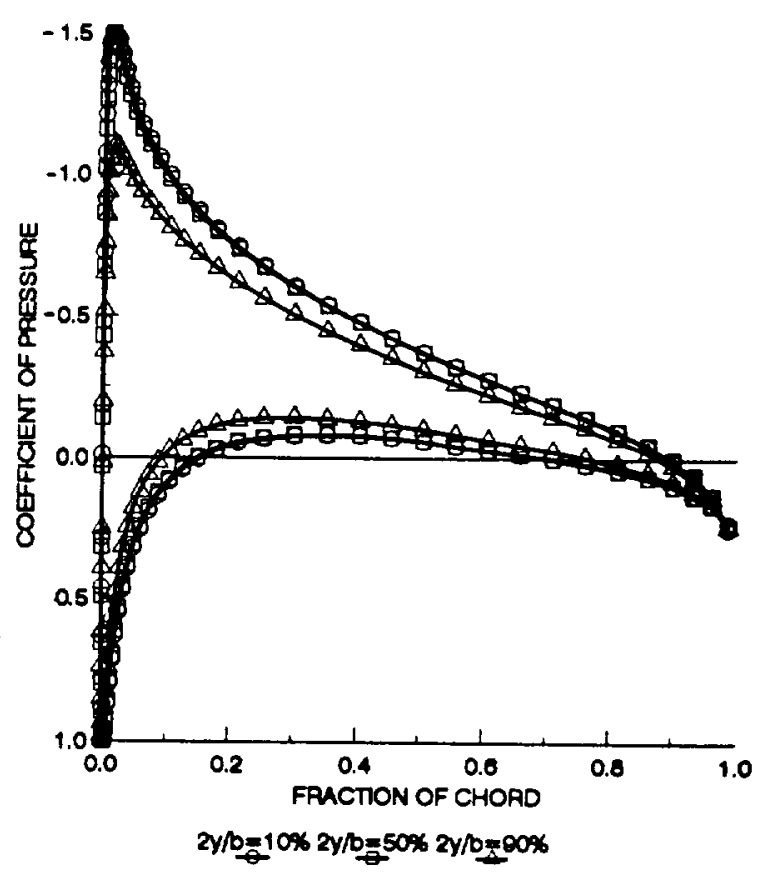

(c) Aspect ratio $=16$; taper ratio $=1$; wing sweep angle $=0^{\circ}$.

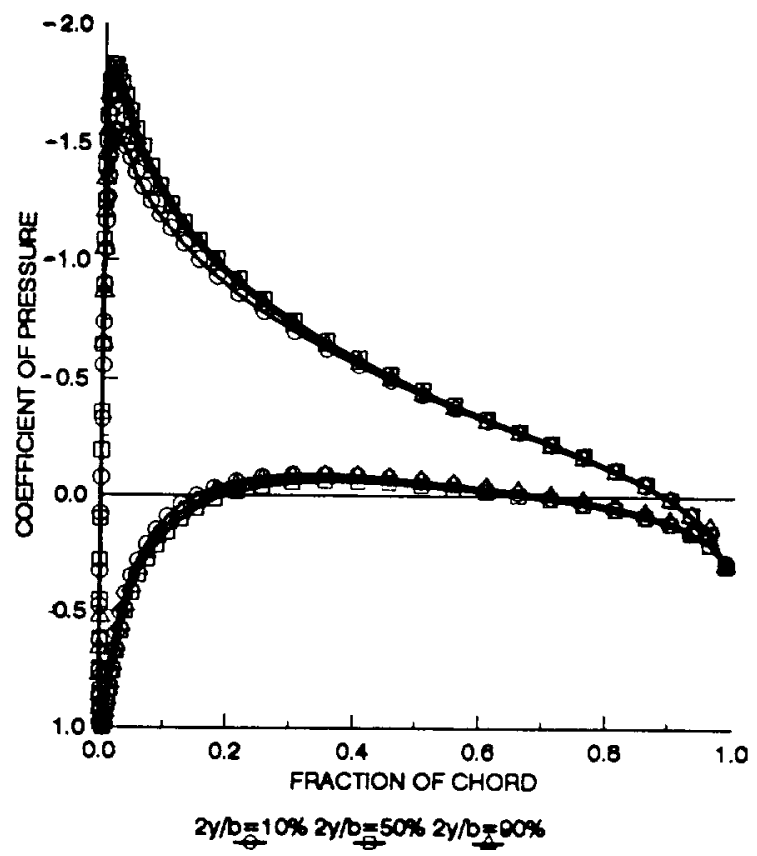

(d) Aspect ratio $=16$; taper ratio $=0.5$; wing sweep angle $=30^{\circ}$.

Figure 5. - Predicted variation of surface pressure along span of NACA 0012. Angle of attack of wing root $=4^{\circ}$ (LEWICE3D). 


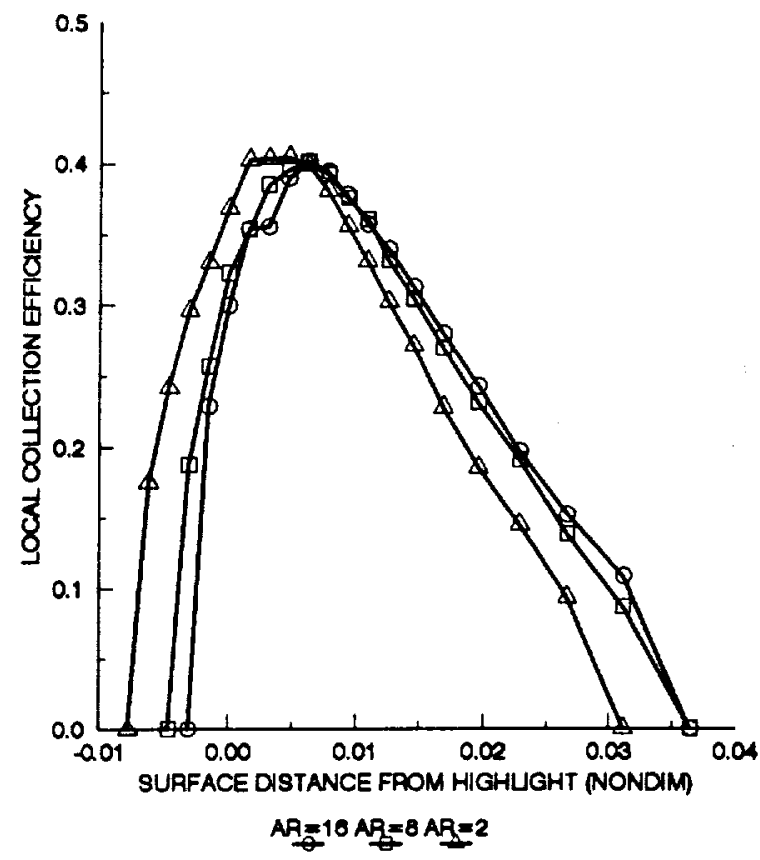

Figure 6. - Variation of Local Collection Efficiency with aspect ratio.

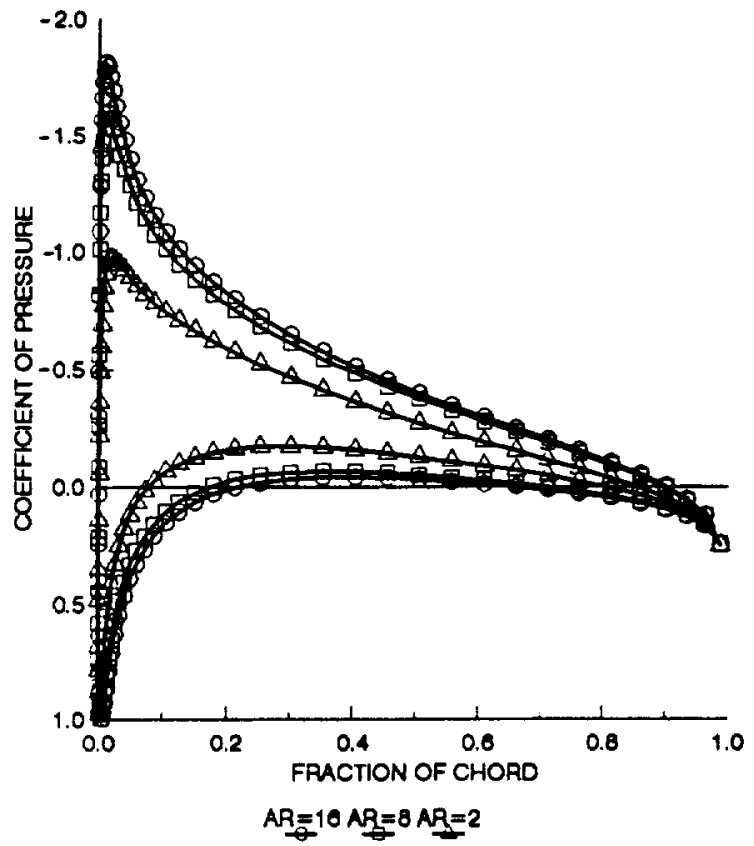

Figure 7. - Variation of surface pressure with as pect ratio.

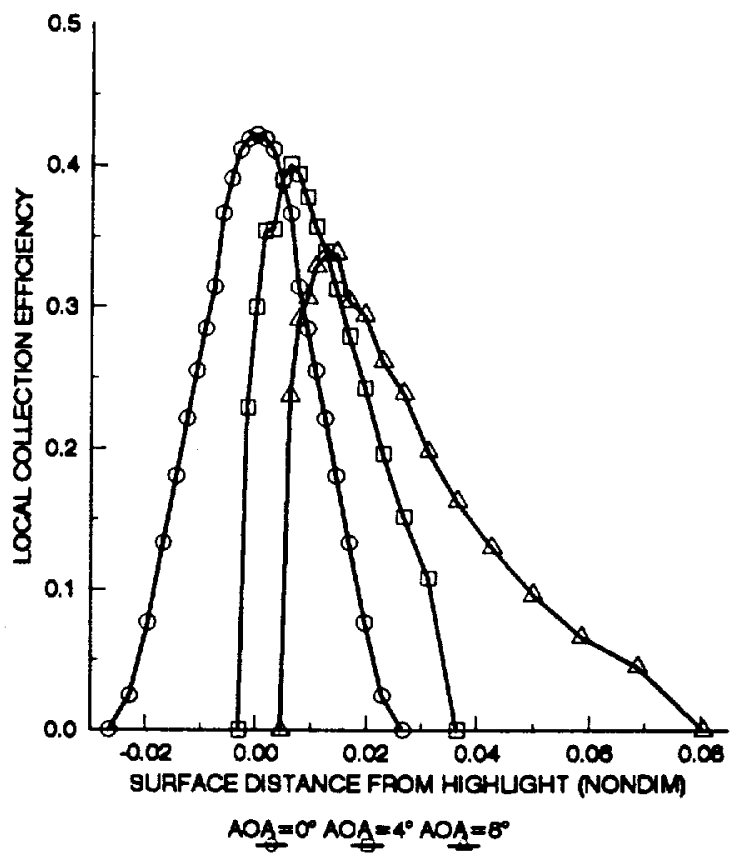

Figure 8. - Variation of Local Collection Efficiency with angle of attack.

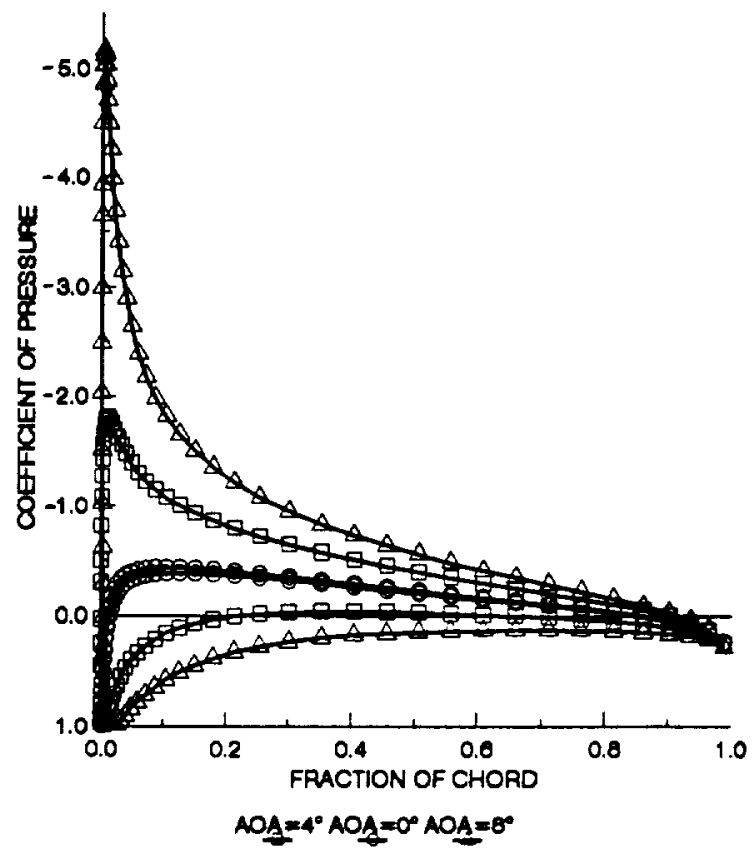

Figure 9. - Variation of surface pressure with angle of attack. 


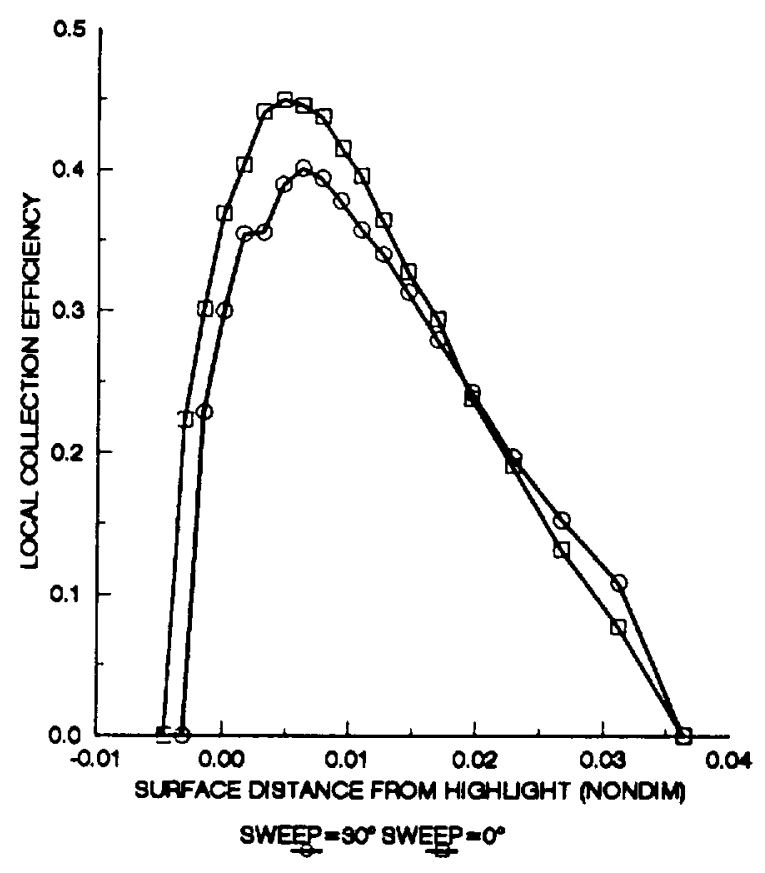

Figure 10. - Predicted variation of Local Collection Efficlency with wing sweep angle at $2 \mathrm{y} / \mathrm{b}=50 \%$ location (LEWICE3D).

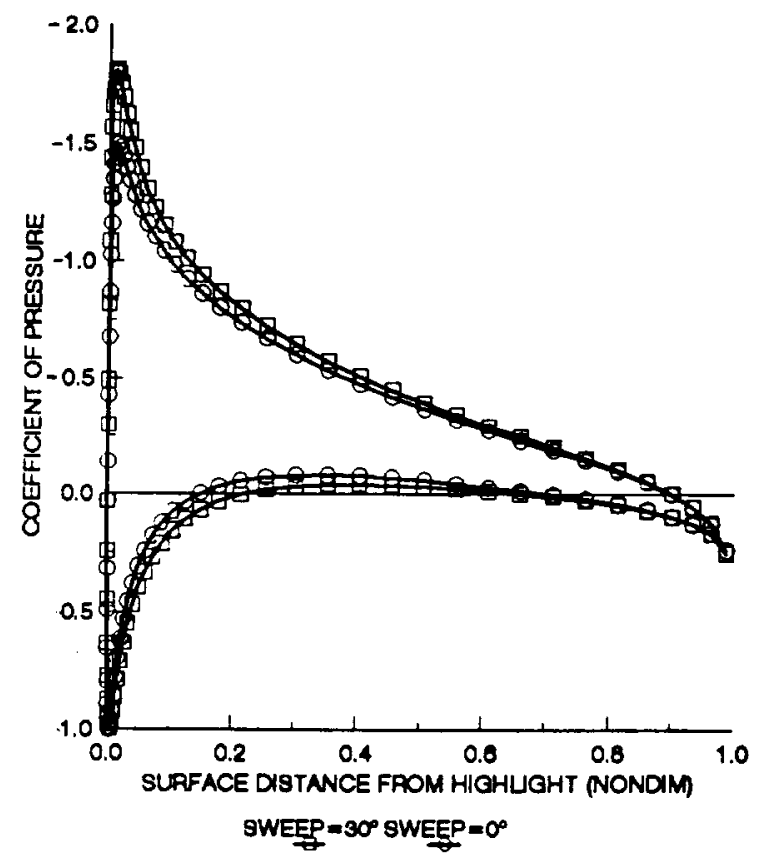

Figure 11. - Predicted variation of surface pressures with wing sweep at $2 \mathrm{y} / \mathrm{b}=50 \%$ location (LEWICESD).

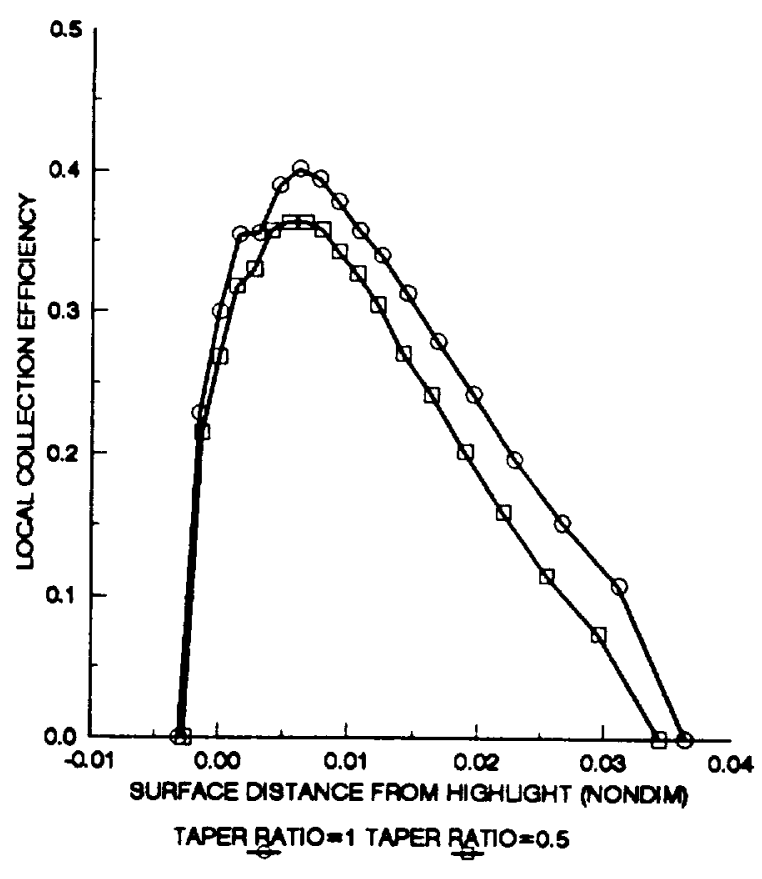

Figure 12. - Predicted variation of Local Collection Efficiency with taper ratio at $2 \mathrm{y} / \mathrm{b}=50 \%$ location (LEWICE3D).

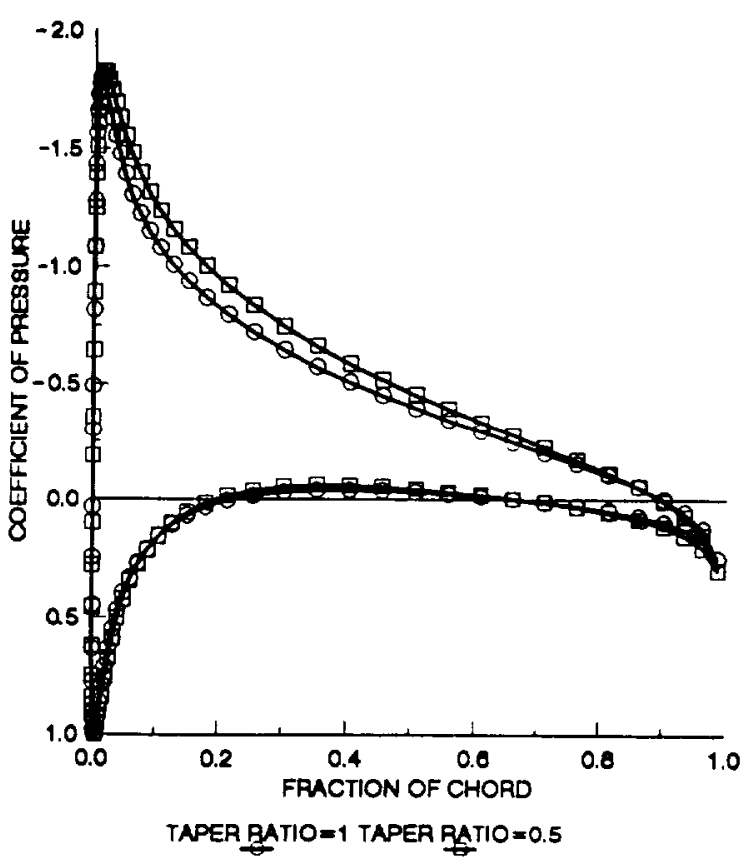

Figure 13. - Predicted variation of surface pressures with taper ratio at $2 y / b=50 \%$ location (LEWICE3D). 


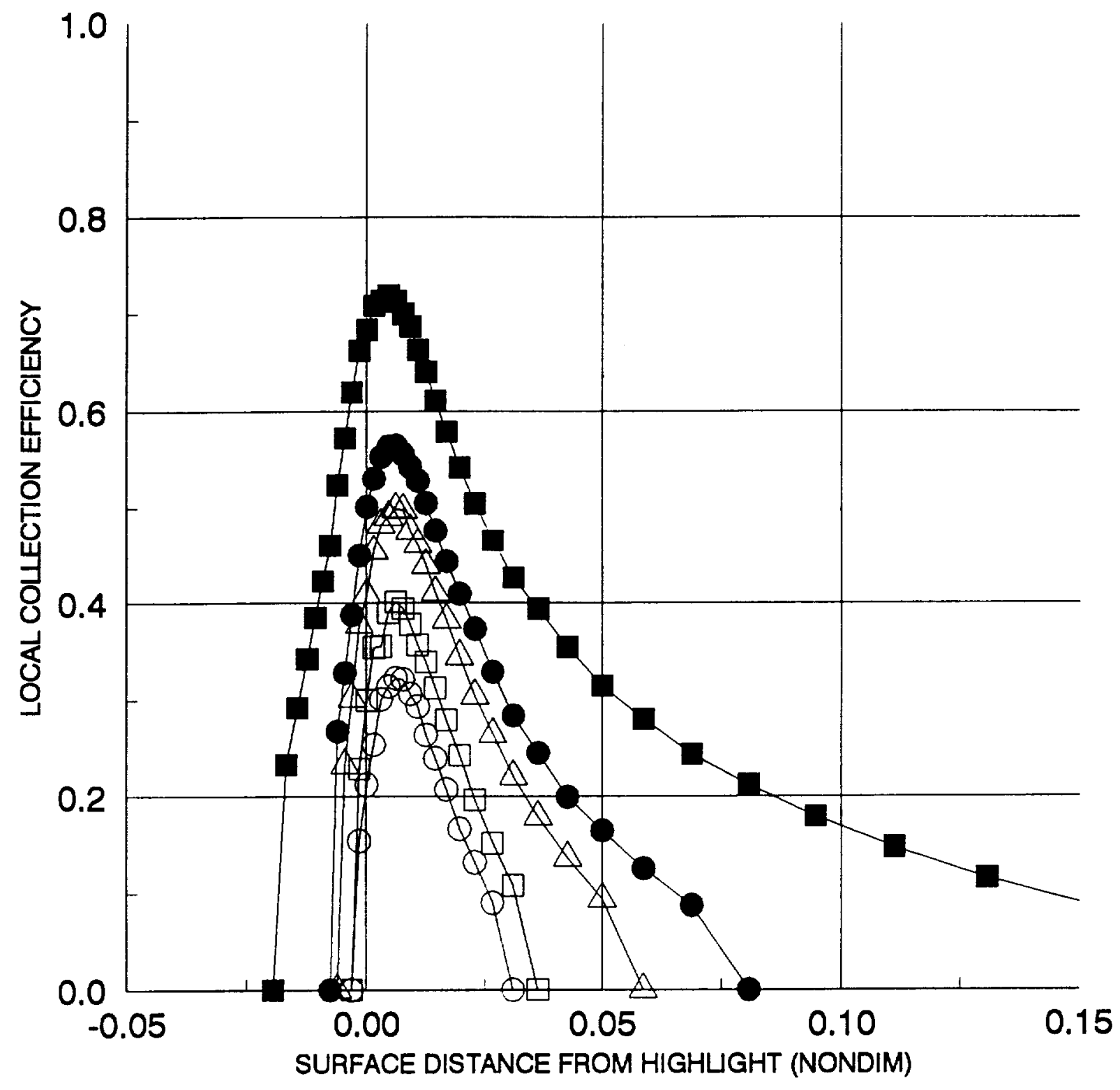

15 MICRON DIAMETER 20 MICRON DIAMETER 30 MICRON DIAMETER

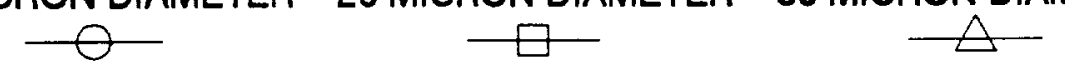

40 MICRON DIAMETER 100 MICRON DIAMETER

Figure 14. - Predicted variation of Local Collection Efficiency with droplet size at $2 y / b=50 \%$ location (LEWICE3D). Aspect ratio $=16$, taper ratio $=1$, wing sweep angle $=30^{\circ}$, airspeed $=134 \mathrm{~m} / \mathrm{s}(300 \mathrm{mph})$, root chord $=4 \mathrm{~m}$.

Angle of attack of root chord $=4^{\circ}$. 


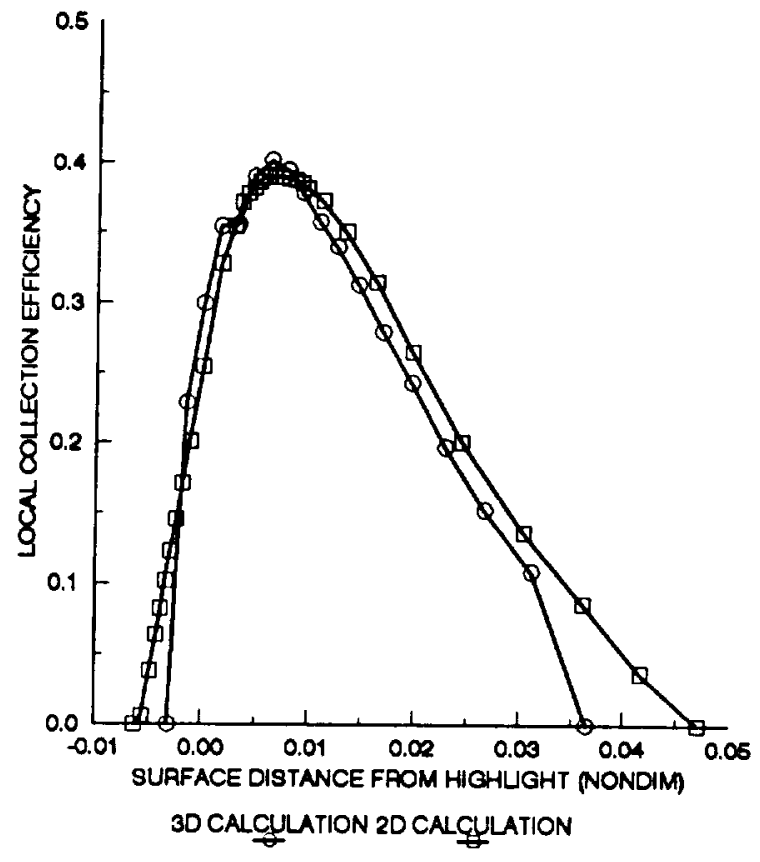

(a) Local Collection Efficiency for 20 micron droplets, free-stream velocity of $134 \mathrm{~m} / \mathrm{s}$ (300 mph).

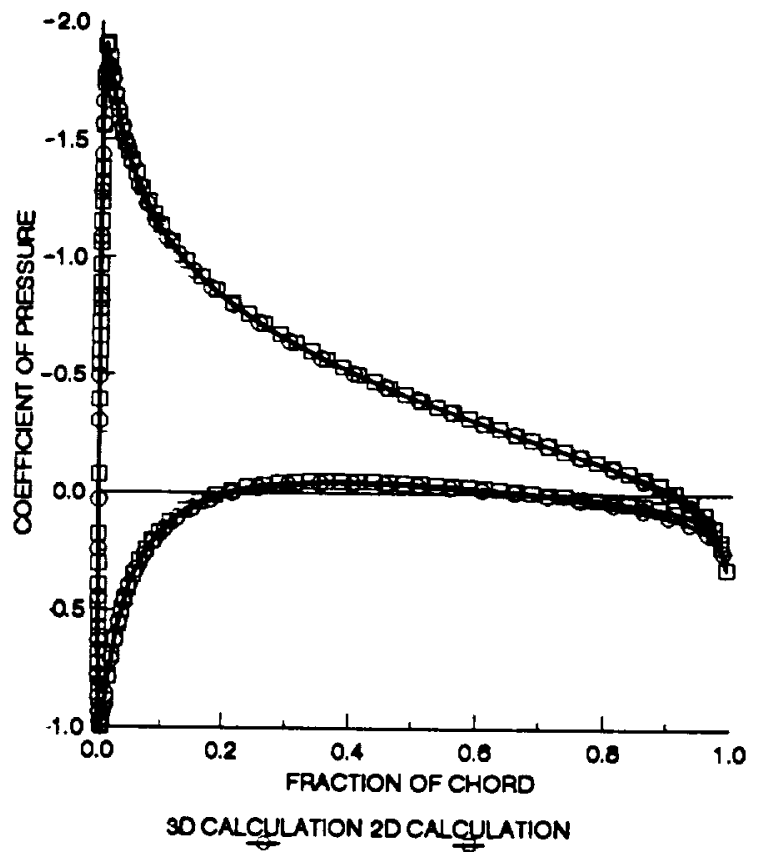

(b) Surface pressure calculations based on free-stream component normal to leading edge.

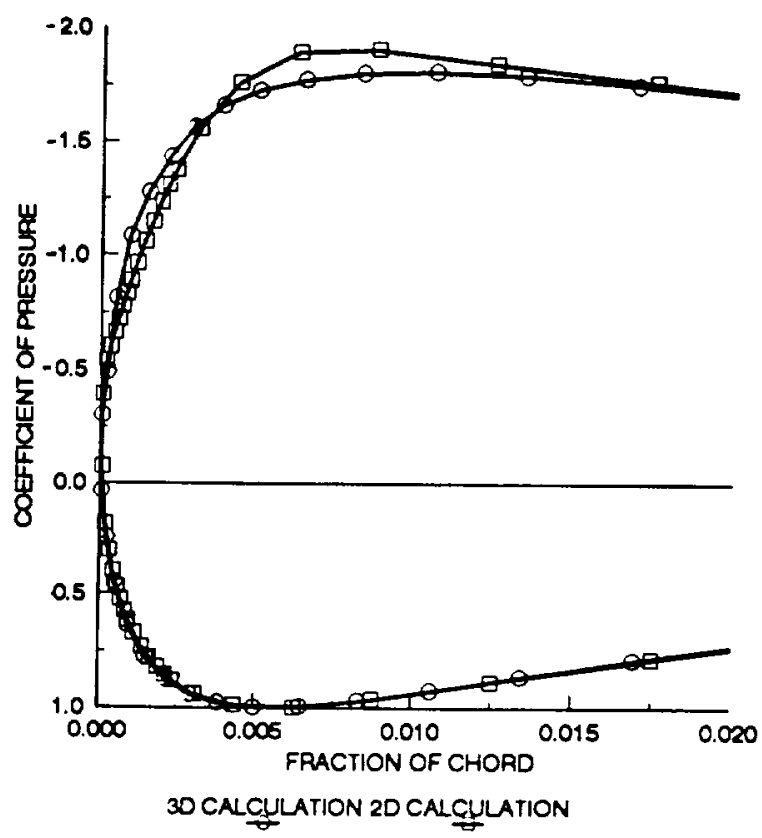

(c) Close-up of Figure (b) near leading edge.

Figure 15. - Comparison of Local Collection Efficiencies and surface pressures predicted by LEWICE and LEWICE3D for baseline case: $30^{\circ}$ swept NACA 0012 , root chord angle of attack $=4^{\circ}$, aspect ratio $=16$, taper ratio $=1$. Calculation at $2 y / b=50 \%$ location. 

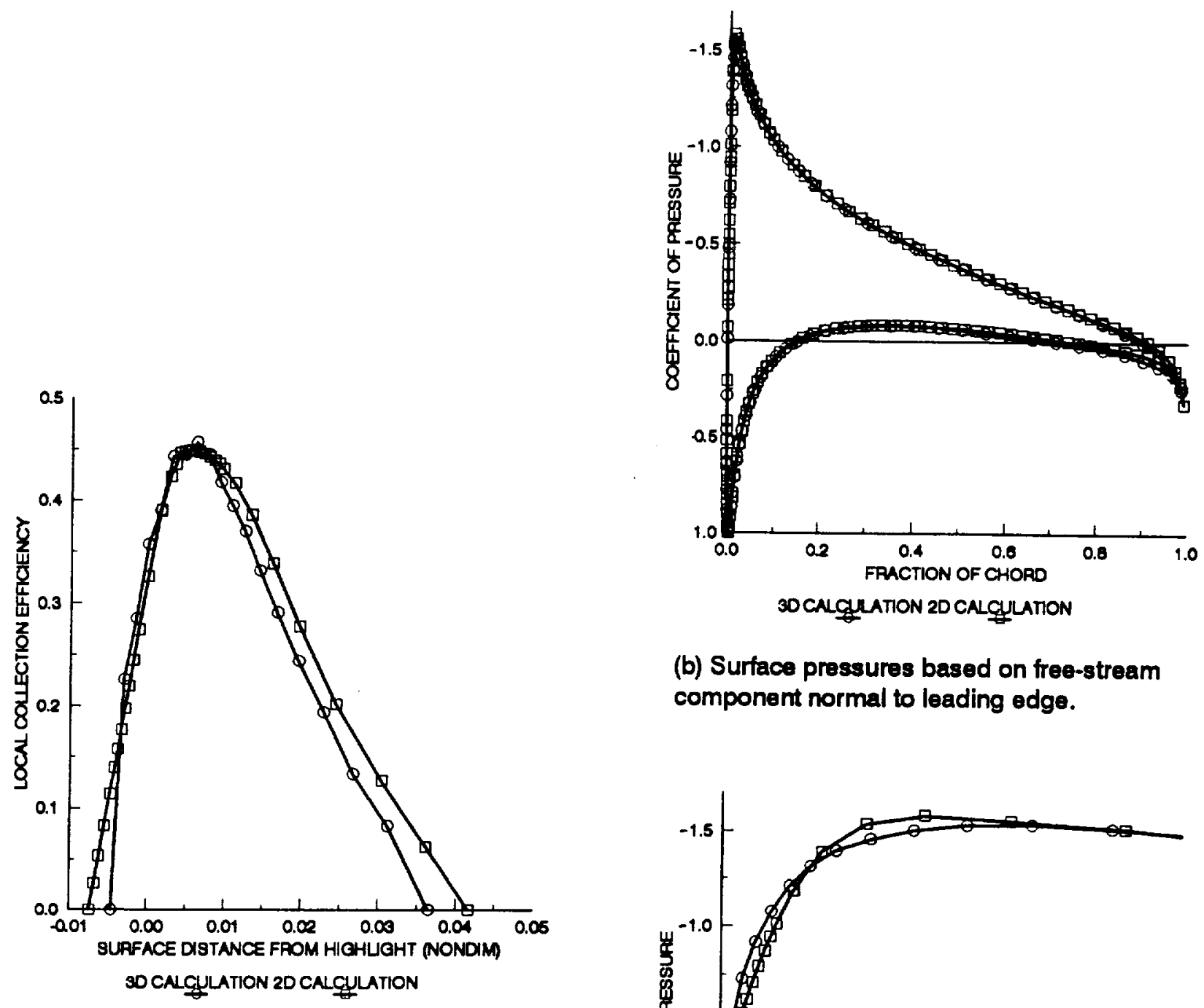

(b) Surface pressures based on free-stream component normal to leading edge.

(a) Local Collection Efficiency for 20 micron droplets, free-stream velocity $=134 \mathrm{~m} / \mathrm{s}$ (300 mph).

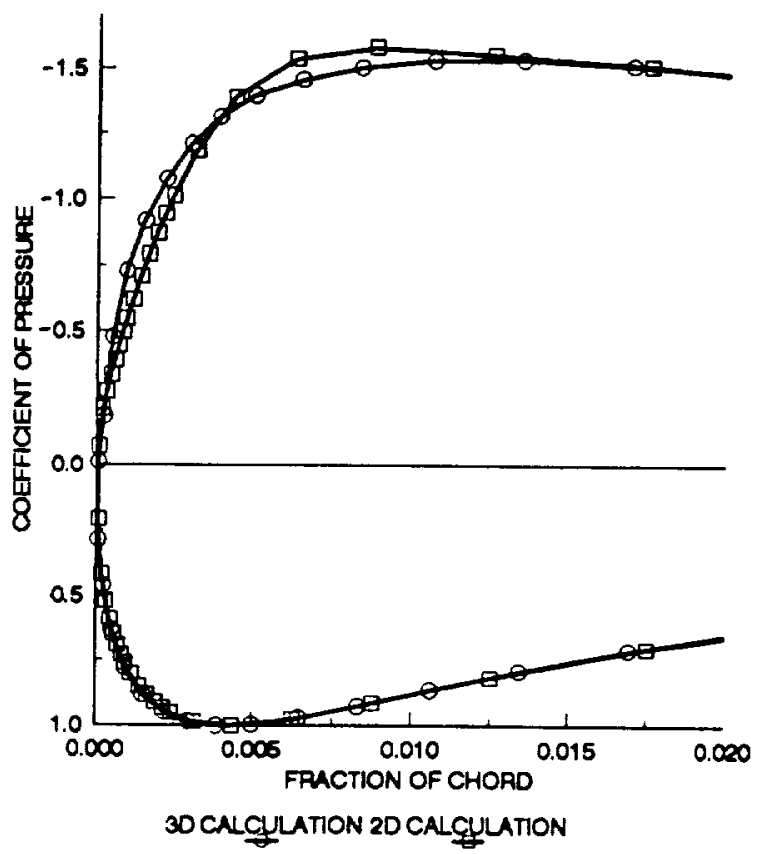

(c) Close-up of Figure (b) near leading edge.

Figure 16. - Comparison of predicted Local Collection Efficiencies and surface pressures for unswept NACA 0012 wing. Spanwise location is $2 y / b=10 \%$, angle of attack of root chord $=4^{\circ}$, aspect ratio $=16$, taper ratio $=1$. 


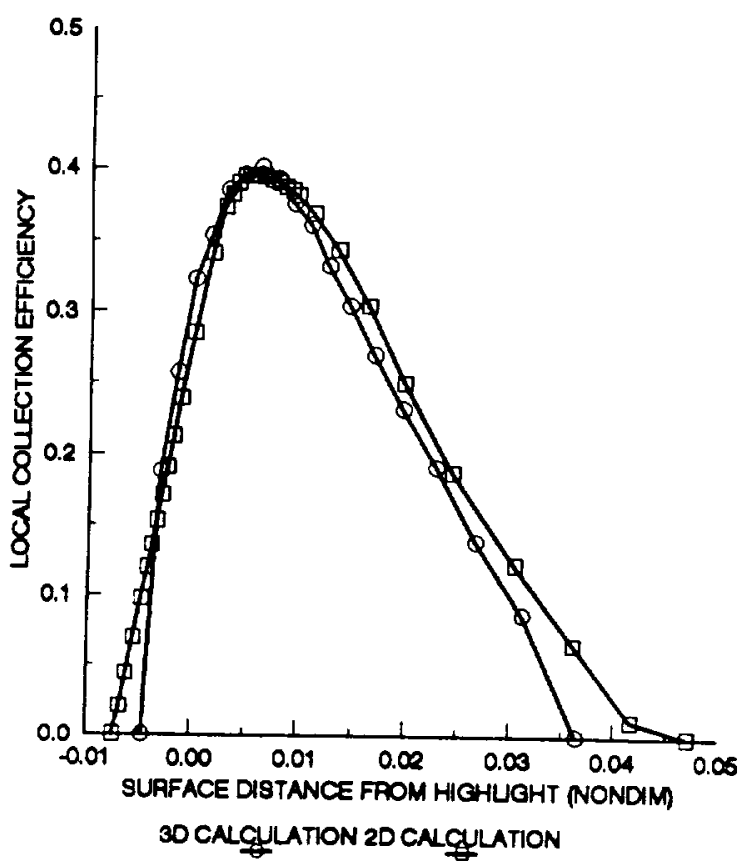

(a) Aspect ratio $=8$.

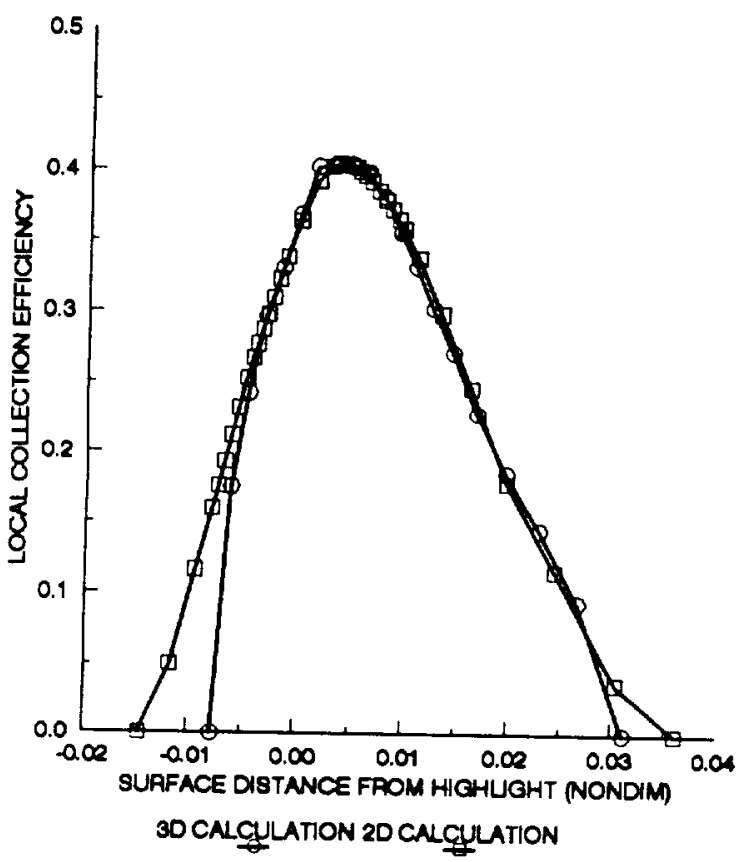

(b) Aspect ratio $=2$.

Figure 17. - Comparison of Local Collection Efficiencies predicted by LEWICE with LEWICE3D at $2 y / b=50 \%$ location for different aspect ratios. NACA 0012 swept $30^{\circ}$, taper ratio $=1$, airspeed $=134 \mathrm{~m} / \mathrm{s}(300 \mathrm{mph}), 20$ micron droplets.

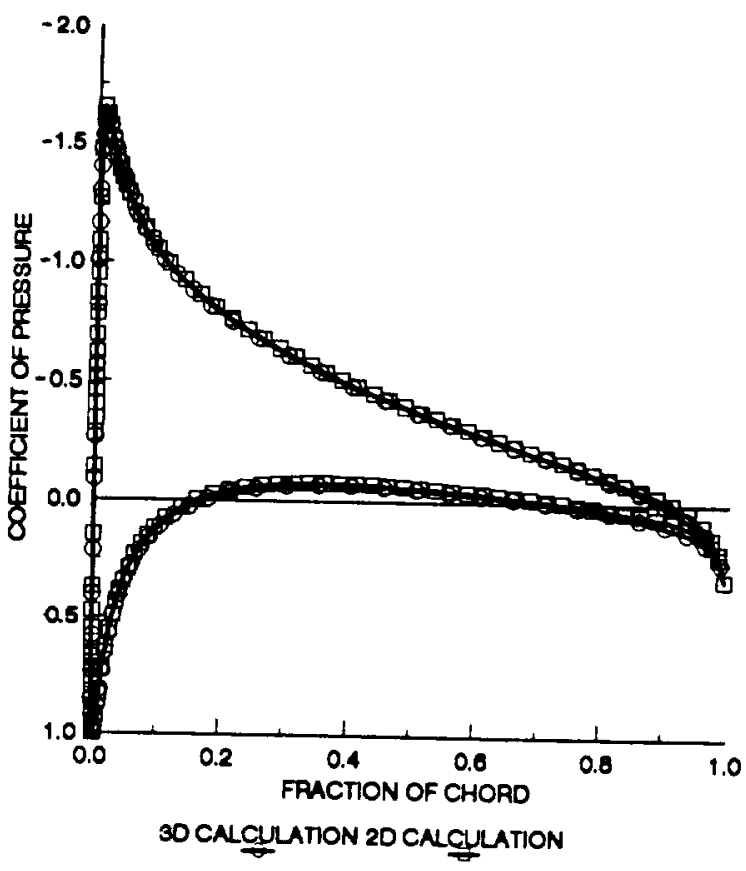

(a) Aspect ratio $=8$.

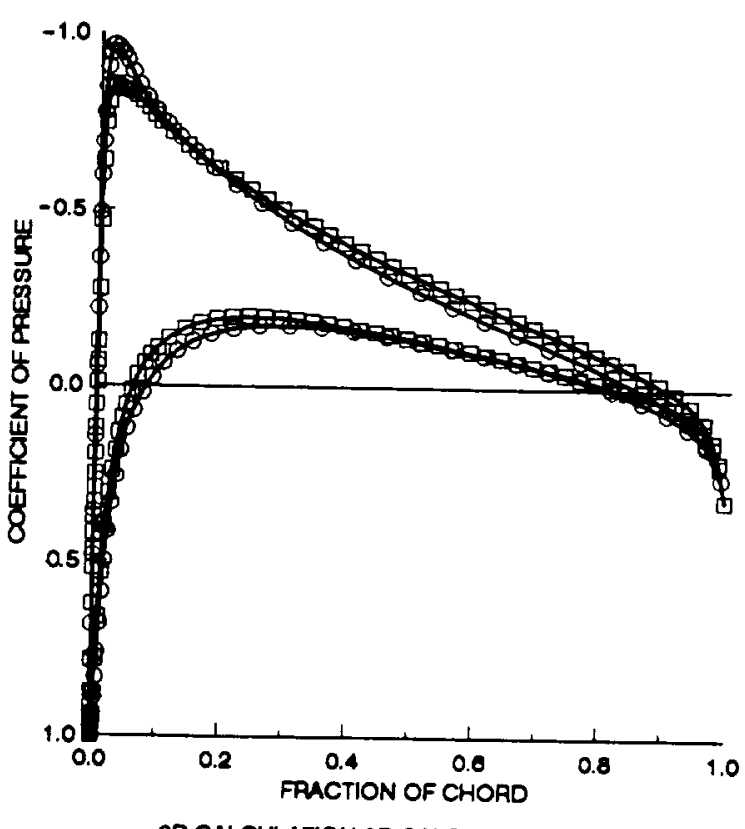

30 CALCUUATION 2D CALCULATION

(b) Aspect ratio $=2$.

Figure 18. - Comparison of surface pressures predicted by LEWICE with LEWICE3D at $2 y / b=50 \%$ location for different aspect ratios. 


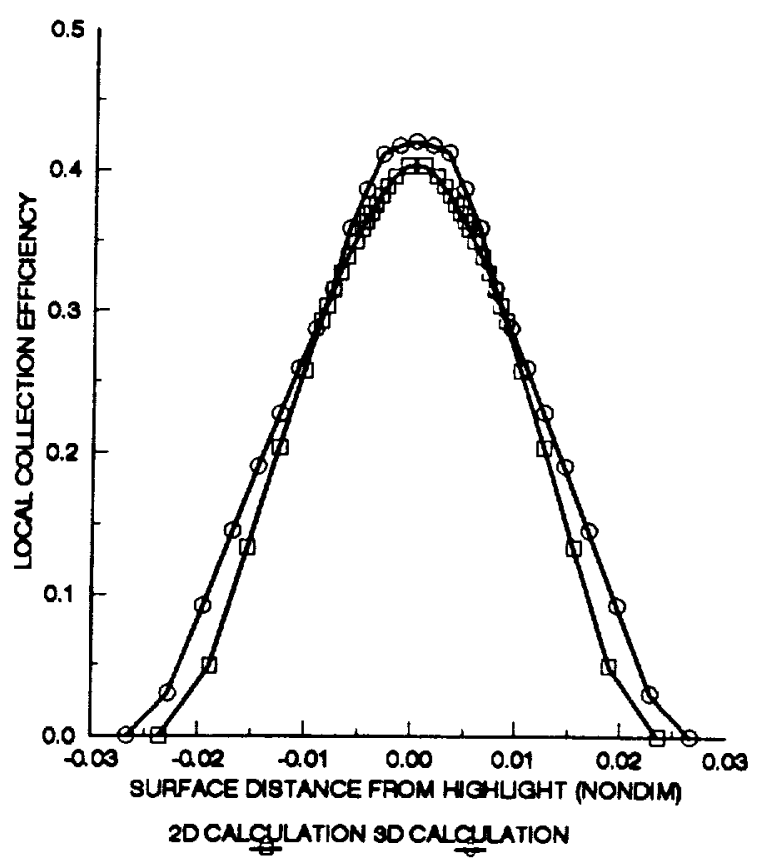

(a) Angle of attack $=0^{\circ}$.

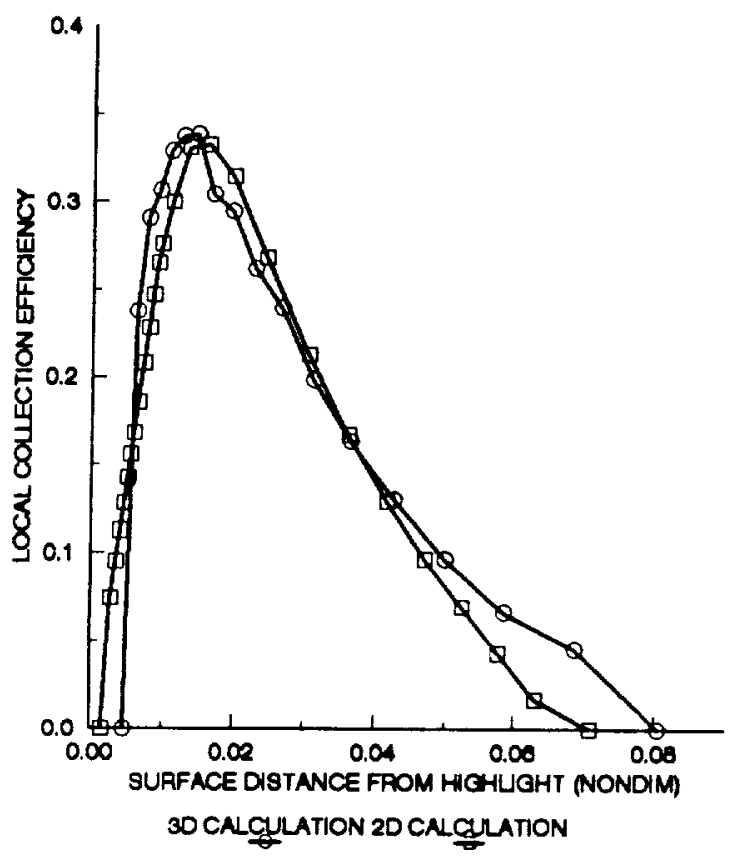

(b) Angle of attack $=8^{\circ}$.

Figure 19. - Comparison of predicted Local Collection Efficiency of LEWICE with LEWICE3D at different angles of attack at $2 \mathrm{y} / \mathrm{b}=50 \%$ location. NACA 0012 swept $30^{\circ}$, aspect ratio $=8$, taper ratio $=1$, airspeed $=134 \mathrm{~m} / \mathrm{s}$ (300 mph); 20 micron droplets.

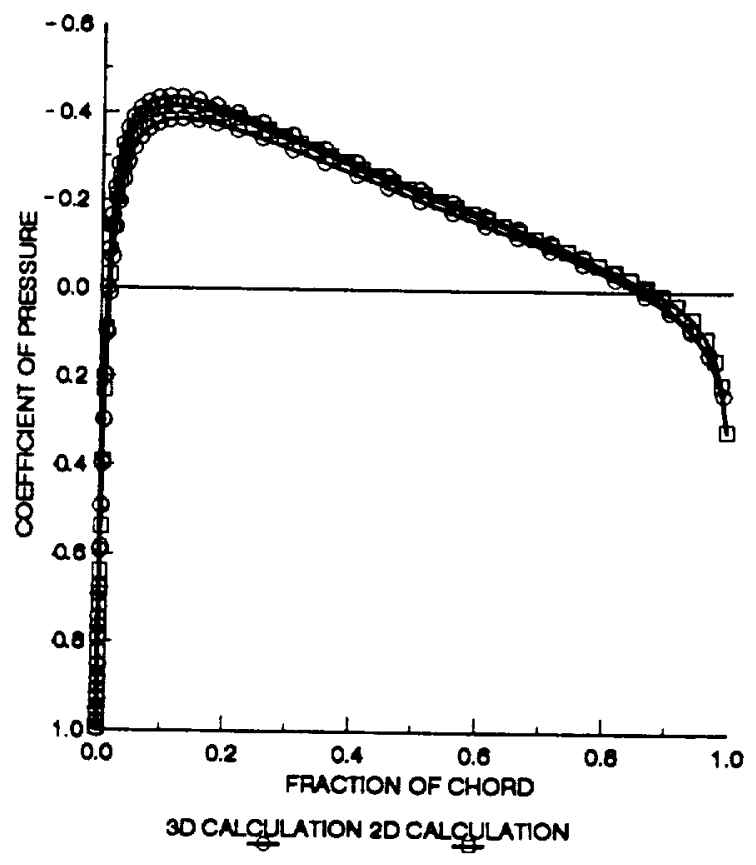

(a) Angle of attack $=0^{\circ}$.

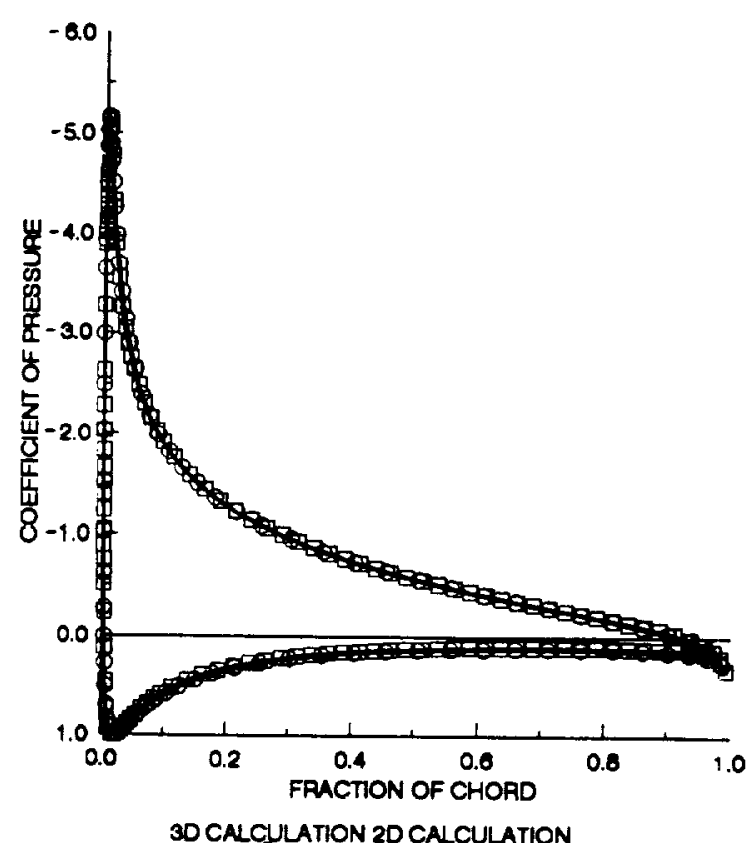

(b) Angle of attack $=8^{\circ}$.

Figure 20. - Comparison of predicted surface pressures of LEWICE with LEWICE3D at different angles of attack at $2 y / b=50 \%$ location. 


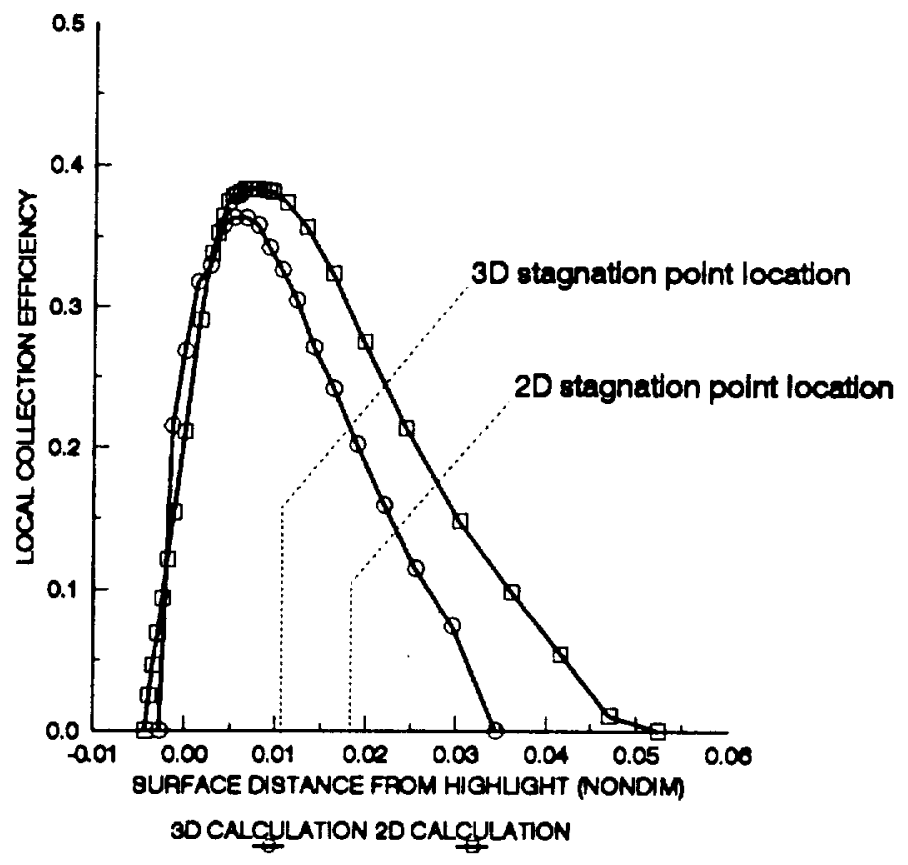

(a) Local Collection Efficlencies for 20 micron droplets and free-stream velocity of $134 \mathrm{~m} / \mathrm{s}$ (300 mph).

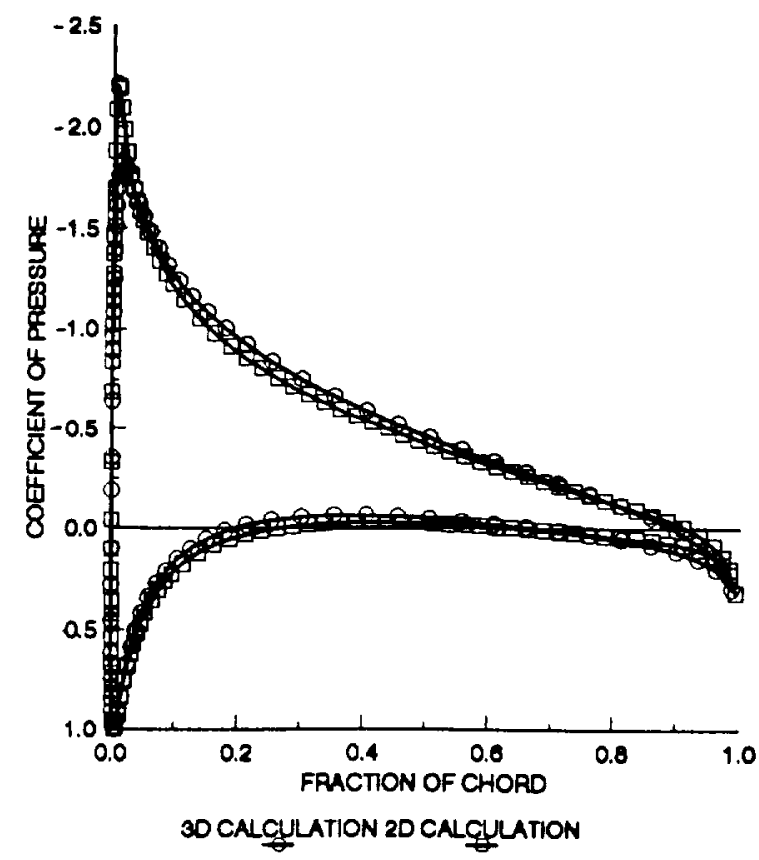

(b) Surface pressure calculation based on component of free stream normal to leading edge.

Figure 21. - Comparison of Local Collection Efficiencies and surface pressures predicted by LEWICE and LEWICE3D for NACA 0012 with taper ratio $=0.5$. Calculations for $2 y / b=50 \%$ location, $30^{\circ}$ wing sweep, aspect ratio $=16$, root chord angle of attack $=4^{\circ}$. 


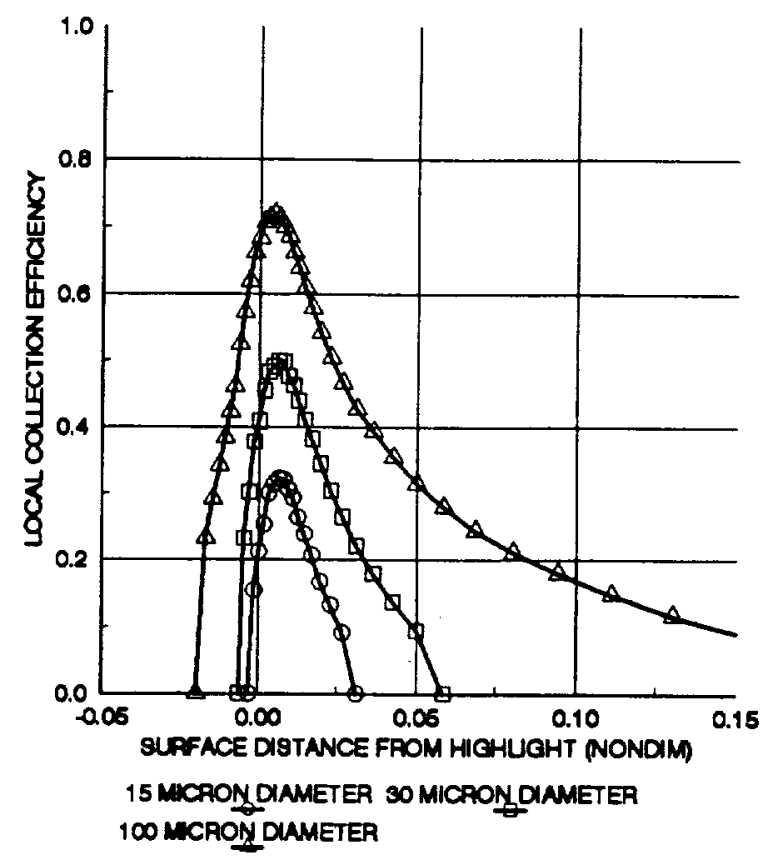

(a) 3D calculation

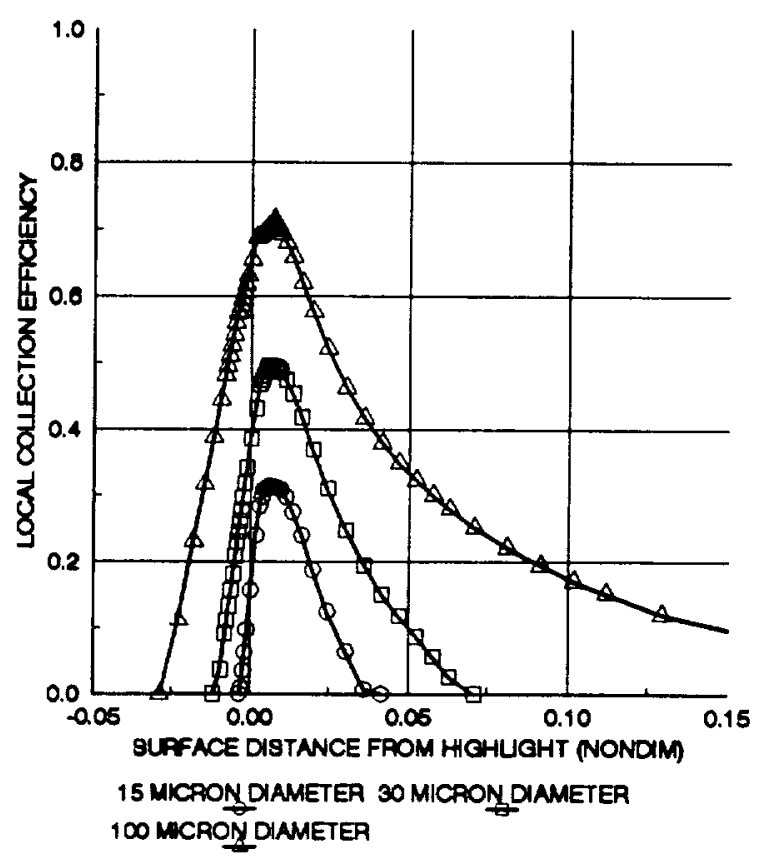

(b) 2D calculation.

Figure 22. - Comparison of variation of Local Collection Efficiency with droplet size predicted LEWCE and LEWICE3D for NACA 0012. Spanwise bcation $2 y / b=50 \%$, wing sweep $=30^{\circ}$, aspect ratio $=16$, taper ratio $=1$, free-stream velocity $=134 \mathrm{~m} / \mathrm{s}(300 \mathrm{mph})$, angle of attack of root chord $=4^{\circ}$. 

Public reporting burden for this collection of information is estimated to average 1 hour per response, including the time for reviewing instructions, searching existing data sources, gathering and maintaining the data needed, and completing and reviewing the collection of intormation. Send comments regarding this burden estimate or any other aspect of this collection of information, including suggestions for reducing this burden, to Washington Headquarters Services, Directorate for intormation Operations and Reports, 1215 Jefterson Davis Highway, Suite 1204. Artington, VA 22202-4302, and to the Ottice of Management and Buoget, Paperwork Reduction Project (0704-0188), Washington, DC 20503

\begin{tabular}{|l|r|r|}
\hline 1. AGENCY USE ONLY (Leave blank) & $\begin{array}{r}\text { 2. REPORT DATE } \\
1992\end{array}$ & $\begin{array}{r}\text { 3. HEPORT TYPE AND DATES COVERED } \\
\text { Technical Memorandum }\end{array}$ \\
\hline
\end{tabular}

4. TITLE AND SUBTITLE

5. FUNDING NUMBERS

Comparison of Two-dimensional and Three-dimensional Droplet Trajectory

Calculations in the Vicinity of Finite Wings

6. AUTHOR(S)

Stanley R. Mohler, Jr. and Colin S. Bidwell

WU-505-68-10

\section{PERFORMING ORGANIZATION NAME(S) AND ADDRESS(ES)}

National Aeronautics and Space Administration

Lewis Research Center

Cleveland, Ohio 44135-3191

8. PERFORMING ORGANIZATION REPORT NUMBER

E-6806

9. SPONSORING/MONITORING AGENCY NAMES(S) AND ADDRESS(ES)

10. SPONSORING/MONITORING AGENCY REPORT NUMBER

National Aeronautics and Space Administration

Washington, D.C. 20546-0001

NASA TM -105617

AIAA-92-0645

11. SUPPLEMENTARY NOTES

Prepared for the 30th Aerospace Sciences Meeting sponsored by the American Institute of Aeronautics and Astronautics, Reno, Nevada, January 6-9, 1992. Stanley R. Mohler, Sverdrup Technology, Inc., Lewis Research Center Group, 2001 Aerospace Parkway, Brook Park, Ohio 44142. Colin S. Bidwell, NASA Lewis Research Center. Responsible person, Colin S. Bidwell, (216) 433-3947.

12a. DISTRIBUTION/AVAILABILITY STATEMENT

12b. DISTRIBUTION CODE

Unclassified - Unlimited

Subject Category 34

13. ABSTRACT (Maximum 200 words)

Computational predictions of ice accretion on flying aircraft most commonly rely on modeling in two dimensions (2D). These $2 \mathrm{D}$ methods treat an aircraft geometry either as wing-like with infinite span, or as an axisymmetric body. Recently, fully three-dimensional (3D) methods have been introduced that model an aircraft's true 3D shape. Because 3D methods are more computationally expensive than 2D methods, 2D methods continue to be widely used. However, a 3D method allows us to investigate whether it is valid to continue applying 2D methods to a finite wing. The extent of disagreement between LEWICE, a 2D method, and LEWICE3D a 3D method, in calculating Local Collection Efficiencies at the leading edge of fininte wings is investigated in this paper.

14. SUBJECT TERMS

Icing; Droplet; Impingement; Trajectory 15. NUMBER OF PAGES 34

16. PAICE CODE

17. SECURITY CLASSIFICATION
OF REPORT
Unclassified

18. SECURITY CLASSIFICATION
OF THIS PAGE
Unclassified
19. SECUAITY CLASSIFICATION OF ABSTRACT Unclassified

